Published in final edited form as:

Chaumel, J., Schotte, M., Bizzarro, J. J., Zaslansky, P., Fratzl, P., Baum, D., et al. (2020). Co-aligned chondrocytes: zonal morphological variation and structured arrangement of cell lacunae in tessellated cartilage. Bone, 134: 115264. doi:10.1016/j.bone.2020.115264.

\title{
Co-aligned chondrocytes: Zonal morphological variation and structured arrangement of cell lacunae in tessellated cartilage
}

Júlia Chaumel, Merlind Schotte, Joseph J. Bizzarro, Paul Zaslansky, Peter Fratzl, Daniel Baum, Mason N. Dean

Highlights

- Stingray cartilage is covered in mineralized tiles (tesserae), filled with cells.

- Cell lacunae vary in shape and size according to location within tesserae.

- Lacunae are aligned to one another, to neighbor tesserae, to local collagen fibers.

- Lacunae density is significantly higher in larger/older tesserae and near pores.

-Stingray cells do not proliferate, hypertrophy or die during mineralization. 


\section{Co-aligned chondrocytes: Zonal morphological variation and structured arrangement of cell lacunae in tessellated cartilage}

Júlia Chaumel ${ }^{1}$, Merlind Schotte ${ }^{2}$, Joseph J. Bizzarro ${ }^{3}$, Paul Zaslansky ${ }^{4}$, Peter Fratzl ${ }^{1}$, Daniel Baum ${ }^{2}$, Mason N. Dean ${ }^{1}$

${ }^{1}$ Department of Biomaterials, Max Planck Institute of Colloids and Interfaces, Am Mühlenberg 1, 14476, Potsdam (Germany). julia.chaumel@mpikg.mpg.de / mason.dean@mpikg.mpg.de

${ }^{2}$ Visual Data Analysis Department, Zuse Institute Berlin, Takustrasse 7, 14195, Berlin (Germany). schotte@zib.de / baum@zib.de

${ }^{3}$ Institute of Marine Sciences, University of California Santa Cruz, Santa Cruz, California (USA). joe.bizzarro@noaa.gov

${ }^{4}$ Charité Hospital, Universitätsmedizin Berlin, Assmannshauser Strasse, 14497, Berlin (Germany).paul.zaslansky@charite.de

Corresponding author: Júlia Chaumel, Department of Biomaterials, Max Planck Institute of Colloids and Interfaces, Am Mühlenberg 1, 14476, Potsdam (Germany)

E-mail: julia.chaumel@mpikg.mpg.de

Keywords: lacunocanalicular network; cell morphology; cell orientation; elasmobranch; tesserae

Abbreviations: Lacunocanalicular network (LCN) 


\begin{abstract}
In most vertebrates the embryonic cartilaginous skeleton is replaced by bone during development. During this process, cartilage cells (chondrocytes) mineralize the extracellular matrix and undergo apoptosis, giving way to bone cells (osteocytes). In contrast, sharks and rays (elasmobranchs) have cartilaginous skeletons throughout life, where only the surface mineralizes, forming a layer of tiles (tesserae). Elasmobranch chondrocytes, unlike those of other vertebrates, survive cartilage mineralization and are maintained alive in spaces (lacunae) within tesserae. However, the function(s) of the chondrocytes in the mineralized tissue remain unknown. Applying a custom analysis workflow to high-resolution synchrotron microCT scans of tesserae, we characterize the morphologies and arrangements of stingray chondrocyte lacunae, using lacunar morphology as a proxy for chondrocyte morphology. We show that the cell density is comparable in unmineralized and mineralized tissue from our study species and that cells maintain the similar volume even when they have been incorporated into tesserae. This discovery supports previous hypotheses that elasmobranch chondrocytes, unlike those of other taxa, do not proliferate, hypertrophy or undergo apoptosis during mineralization. Tessera lacunae show zonal variation in their shapes-being flatter further from and more spherical closer to the unmineralized cartilage matrix and larger in the center of tesserae- and show pronounced organization into parallel layers and strong orientation toward neighboring tesserae. Tesserae also exhibit local variation in lacunar density, with the density considerably higher near pores passing through the tesseral layer, suggesting pores and cells interact (e.g. that pores contain a nutrient source). We hypothesize that the different lacunar types reflect the stages of the tesserae formation process, while also representing local variation in tissue architecture and cell function. Lacunae are linked by small passages (canaliculi) in the matrix to form elongate series at the tesseral periphery and tight clusters in the center of tesserae, creating a rich connectivity among cells. The network arrangement and the shape variation of chondrocytes in tesserae indicate that cells may interact within and between tesserae and manage mineralization differently from chondrocytes in other vertebrates, perhaps performing analogous roles to osteocytes in bone.
\end{abstract}




\section{Introduction}

The vast majority of adult vertebrate animals - approximately $98 \%$ of species - have skeletons made of bone and cartilage [1]. Whereas bone comprises the majority of the adult skeleton, cartilage is more sparsely distributed, serving as a thin bearing layer in joints and providing skeletal support for flexible structures such as noses, ears and costal cartilages [2]. Just as the functional roles of bone and cartilage differ, so do the functional roles of their cells. In mammals, bone possesses multiple cell types (osteoblasts, osteoclasts, osteocytes and bone lining cells), responsible for the active control of tissue architecture and its mineral homeostasis [3-5]. Mammalian cartilage, on the other hand, contains just one cell type, the chondrocyte. Chondrocytes are responsible for the synthesis and turnover of the large volumes of gel-like extracellular matrix that give cartilage its viscoelastic properties [2,6,7]. In comparison to bone cells, which are richly interconnected with each other and bone's vasculature, chondrocytes in adult mammalian cartilage are often far removed from one another, with limited or no communication [8,9] and no vascular supply, relying entirely on diffusion for nutrient and metabolite transport. As a result, when mammalian chondrocytes undergo apoptosis or transdifferentiate into bone cells during mineralization (e.g. as in endochondral ossification) the resultant mineralized cartilage is often comparatively cell poor and lacks the in-built cell networks characteristic of mammalian bone $[10,11]$.

To quote John Currey [1, pg. 4], "As soon as one looks outside the mammals and birds the situation becomes more complex." When non-mammalian species are considered, there are several indications that vertebrate skeletal cells do not always behave according to the paradigms described above. Sharks and rays (elasmobranch fishes; Fig. 1A), for example, have skeletons that are primarily composed of unmineralized cartilage which, unlike the endoskeletal cartilage of most other vertebrates, is not replaced by bone during ontogeny [12,13]. Elasmobranch cartilage does mineralize, however, forming a thin layer of tiles (tesserae) that ensheath the majority of the skeleton, beneath the fibrous perichondrium (Fig. 1B-D) [14-16]. During the biomineralization process that forms tesserae and unlike in mammalian cartilage mineralization, the chondrocytes do not hypertrophy or undergo apoptosis, but rather are incorporated alive into the mineralized tissue. The chondrocytes are maintained there, within lacunar spaces, surrounded by a small volume of pericellular unmineralized cartilage (Fig. 1D, 2) $[12,17]$.

The persistence of living cells within the mineralized matrix of tesserae was perplexing, until it was shown elasmobranch chondrocyte lacunae can be linked via short canalicular passages. This discovery revealed a degree of connectivity among tesseral chondrocytes (e.g. via continuity of the extracellular matrix between neighboring cell lacunae), suggesting the presence of a chondrocyte network in tesserae [18]. The function of the chondrocyte network in tesserae and the degree to which the chondrocytes interact within it is unknown and to date, no other vertebrate chondrocyte lacuno-canalicular networks (LCNs) have been described. In contrast, the extensive LCN linking osteocytes in bone is considered central to bone biology, particularly for mechanosensation and mechanotransduction, and thereby, bone's ability to reconfigure itself according to its mechanical environment [19]. The gross similarity of bone and chondrocyte LCNs - both involving the linking of cells embedded in a mineralized matrix - and 
chondrocytes being the primary skeletal cell in elasmobranchs, suggest that the elasmobranch chondrocyte LCN could share functions with the osteocyte LCN in bone (e.g. mechanosensation, mineral homeostasis, nutrient transport).

An understanding of the structure of the elasmobranch chondrocyte LCN is vital to deciphering its function. In bone, the osteocyte LCN structure reflects tissue growth processes, local arrangement of collagen fibers and predominant mechanical loading directions [19-21]. The current study is a first step in the characterization of the three-dimensional structural arrangements of the elasmobranch cartilage LCN, focusing on the lacunar portion of the network. Using synchrotron radiation microcomputed tomography (SR- $\mu \mathrm{CT}$ ) scans of tesserae (Fig. 1C, 2A), we quantify the morphology and arrangements of tesserae chondrocyte lacunae in three-dimensions (3D) with high resolution. By characterizing architectural aspects of the tesserae chondrocyte LCN, we follow groundwork laid by bone LCN research, using lacunar arrangements to provide insights into growth processes, ultrastructure and mechanical design of tessellated cartilage, as well as the potential for communication among chondrocytes.

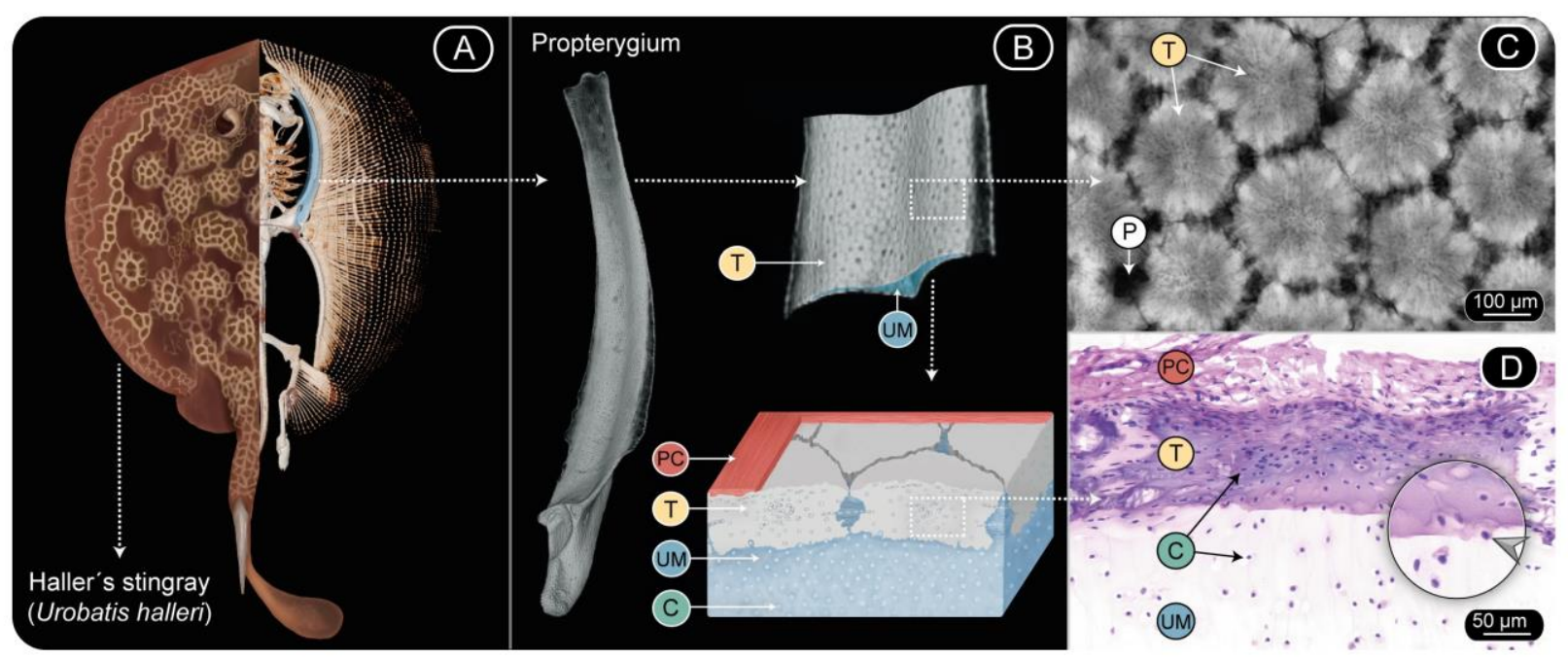

Figure 1. The tessellated cartilage skeleton of the stingray Urobatis halleri. A) Body of the stingray (left) and CT scan of the mineralized skeleton (right), highlighting one of the largest skeletal pieces: the propterygium (in blue). B) $\mu \mathrm{CT}$ scan of the propterygium (left) and a zoomed region (top right), where the outer tessera layer (in gray) can be appreciated, surrounding the unmineralized cartilage matrix (in blue). As shown in the schematic of tessellated cartilage (bottom), the tesserae are situated atop the unmineralized cartilage matrix and further wrapped by the perichondrium. C) Projection image of a SR$\mu C T$ scan of the tesserae layer. The spaces between the tesserae (intertesseral joints) are filled with unmineralized fibers and matrix (not visible here), with larger pores periodically perforating the tessellated layer. D) Hematoxylin-Eosin histological staining of a lateral section of one tessera, showing unmineralized matrix and perichondrium. Cells are located both in the unmineralized matrix and within lacunae inside the tesserae; a cell from the unmineralized cartilage being incorporated into the tessera is marked by an arrowhead in the zoom inset. Abbreviations: Cells (C), Perichondrium (PC), Pore (P), Tesserae (T), Unmineralized Matrix (UM). 


\section{Material and methods}

\subsection{Specimens}

Skeletal samples of the propterygium were collected from two adult Haller's round stingrays (Urobatis halleri), a $19 \mathrm{~cm}$ disc width (DW) female and a $21.4 \mathrm{~cm}$ DW male. The propterygium is

a large skeletal element at the base of the wing, essentially a triangular rod of cartilage with a tessellated covering, offering comparatively long, flat sides from which to harvest tesserae (Fig. 1B). Urobatis halleri was chosen due to its relatively small size, which facilitates harvesting and imaging tissue. Additionally, $U$. halleri is an established study system for tessellated cartilage biology, with the majority of recent high-resolution, ultrastructural data coming from this species [e.g. 12,13,17,18,22].

As in previous studies of skeletal ultrastructure in this species [e.g. 13,22], samples were donated from another study [23]. Whole animal specimens were shipped on dry ice and stored frozen $\left(-20^{\circ} \mathrm{C}\right)$. After re-thawing in cool water, thick cross-sections of the proximal propterygium were cut and large swaths of tesserae excised by single-edge razor blade. Samples were trimmed, removing the majority of the uncalcified cartilage and then manually pruned down to strips approximately 2-3 tesserae wide and 10-20 tesserae long (Fig. 2A inset) (Urobatis tesserae are typically hundreds of microns wide). Samples were then air-dried and flattened between Teflon blocks (to prevent sticking). The resultant tessellated strips were affixed upright in micro-centrifuge tubes using light-cured dental adhesive and the tubes were glued on screws for mounting for subsequent synchrotron experiments.

\subsection{Synchrotron radiation micro-computed tomography (SR - $\mu C T)$}

Tesserae samples were scanned in synchrotron radiation micro-computed tomography (SR$\mu \mathrm{CT})$ at the BAMline, BESSY II synchrotron source, Helmholtz-Zentrum Berlin für Materialien und Energien (HZB). Samples were equilibrated to humidity and temperature in the scanning hutch for hours prior to scanning to minimize sample movement during scanning. Datasets of 720 or 1440 full-absorption radiographs were collected over $180^{\circ}$ or $360^{\circ}$ rotation, energies of 10-13 keV, and 1.0-1.4 s exposure times, with a sample-to-detector distance of $\sim 3 \mathrm{~mm}$ and effective pixel sizes of $876 \mathrm{~nm}$. The resulting projection images were normalized conventionally using empty-beam images and 3D volumes were reconstructed with PyHST (ESRF, Grenoble France).

\subsection{D image rendering, segmentation and analysis}

\subsubsection{Lacunae segmentation pipeline}

Reconstructed SR- $\mu$ CT data were visualized, segmented and analyzed in an extended version of the visualization software Amira (AmiraZIBEdition 2019.12) [24]. Our air-dried sample preparation technique occasionally resulted in cracks through tesserae. Intact tesserae with minimal or no cracking were chosen from the $19 \mathrm{~cm}$ DW animal $(n=5)$ and from the $21.4 \mathrm{~cm} \mathrm{DW}$ animal $(n=4)$ for analysis. In scan data, lacunar spaces in tesserae were small, dark (low 
intensity value) cavities within the brighter (higher intensity value) tesserae (Fig. 2-3; see also [25]). Chondrocytes were not visible in our scans; however, since cells have been observed to nearly fill tesserae lacunae $[12,13,17,26]$ (see also Fig. 1D inset), we used lacunae as proxies for cell morphology and size. Canaliculi connecting lacunae were often clearly visible in our SR$\mu \mathrm{CT}$ slices. However, the necessity of comparatively large scan volumes (i.e. to encompass multiple tesserae) precluded attaining resolution adequate to reliably visualize all canaliculi in a sample. As a result, canaliculi were removed, when visible, during image processing (see the Contour Tree Segmentation and Manual Proof-reading and Filtering steps in [25]); our analysis therefore was focused only on lacunae and their arrangements.

To quantify lacunar arrangements and morphologies for the population of lacunae within tesserae, individual tesserae were segmented and separated from the background voxels. The lacunae within each tessera were then isolated en masse, and all individual lacunae in a tessera were further isolated as separate, quantifiable objects and their morphologies and spatial relationships quantified. For these segmentation processes (i.e. of tesserae and lacunar spaces), we combined existing algorithmic and semi-automatic segmentation methods into two pipelines, which we describe in detail in [25]; an illustrated, simplified version of the workflow is presented in Figure 2.

\subsubsection{Quantification of morphology and orientation of lacunae}

We quantitatively characterized a variety of morphometric, position, and orientation variables for lacunae. Variables are described in Table 1 and represented visually in Figure 3. The 'lacunar population' variables describe general aspects of the network (e.g. number, density of lacunae), whereas the 'lacunar morphometric' variables describe shape and size of individual lacunae. Both population and morphometric variable types were measured on whole tesserae datasets (i.e. all lacunae in a tessera).

'Lacunar position' and 'lacunar orientation' variables required a local coordinate system that was comparable across datasets (i.e. tesserae with different geometries); therefore, we sub-divided tesserae into so-called 'wedge' datasets that captured comparable sub-populations of lacunae (described below). A tesseral coordinate space was first established to create the wedge datasets. Lacunar position and orientation variables were calculated using a local right-handed coordinate system for each tessera, constructed as follows. From all voxels that had been assigned to a tessera, including the enclosed lacunae (see the 'Segmentation of tesserae' section in [25]), we computed the "center of mass" (i.e., the average position of all tessera voxels) as the origin of the coordinate system. The tessera's $X Y$ plane was oriented parallel to the plane that best approximated the tessera voxels (i.e. that minimized the sum of squared distances of all voxels to that plane), computed using covariance analysis of the tessera voxels. The $Z$ axis was oriented perpendicular to the $X Y$ plane, acting as a chondral-perichondral axis (Fig. 3A-C). The precomputed position of the origin, that is the "center of mass", was visually verified to lie such that the lacunae radiated outwards from it. If this was not the case (e.g. in very irregularly shaped tesserae), the origin was adjusted manually. Note that in such cases, required adjustments were minimal and only the $X$ and $Y$ coordinates of the origin were adjusted. 
Once the tesseral coordinate system was established, the wedge datasets could be defined. The concept of the wedge dataset was built off of an anatomical observation made during preliminary data analysis: across tesseral datasets, lacunae (particularly peripheral lacunae) were observed to exhibit a radial orientation toward the nearest neighbor tessera (see Results and Figure 3D-E), creating groups of co-aligned lacunae arranged at intervals around the tesseral center. This arrangement was verified quantitatively by plotting the variation in the orientation of the primary lacunar axis in the $\mathrm{XY}$ plane in the global coordinate system: Figure $3 \mathrm{D}$ shows the frequency distribution for lacunar orientations plotted with $3^{\circ}$ bin size and with an overlying Gaussian mixture model curve fit generated with the peakfit function in Matlab [27], where the fit with the lowest mean fit error had as many peaks as surrounding neighbor tesserae. The peaks marked on the trendline with arrowheads in Figure 3D correspond to the cell groupings. From these observations, tesserae datasets were divided into wedge datasets according to the contact zones with neighbor tesserae (see 'Fragmentation/Cutting of tesserae cells into single wedges' section in [25]), creating pie-piece-shaped wedges containing those cells oriented toward a specific tessera neighbor (Figure 2E).

The origin of the tesseral coordinate system was also the convergence point for all wedge sectioning planes and therefore the vertex of the XY projections of all wedges in a tessera (Fig. $3 A-C)$. In each wedge dataset, the $X$ axis was situated to connect the centers (i.e. the origins of the coordinate systems) of neighboring tesserae. As a result, in each wedge, the $X$ axis extended in the positive direction toward the tessera neighbor (Fig. 3B-C). The $Y$ axis was therefore situated approximately parallel to the joint face axis. Thus, all wedges share the same $X Y$ plane but differ in the orientation of the $X$ and $Y$ axes. Tesserae were divided into the same number of wedges as they had sides, which also corresponded to the number of surrounding neighbor tesserae (i.e. between five and seven wedges). Tesserae bordering pores were further distinguished (e.g. Fig. 1C). These pores, which periodically perforated the tesseral layer, were typically $>100 \mu \mathrm{m}$ in diameter, irregular in their placement, but always occurred at tesserae triple junctions (the intersection points of three neighboring tesserae; Fig. 1C, 4B). Lacunae near pores were observed to have distinct characteristics (see Results) and so in pore-adjacent tesserae, additional pore-associated wedges were also defined. In other words, a pore-adjacent hexagonal tessera would be comprised of seven wedge datasets: one pore-wedge and six nonpore wedges. The definition of pore wedges allowed examination of the properties of poreassociated lacunae.

The definition of wedge datasets allowed comparison of 'lacunar position' and 'lacunar orientation' variables across diverse tesserae (e.g. five, six and seven-sided tesserae); these variables require slightly more explanation than is given in Table 1 and so are briefly described below. 'Distance from XY plane' and ' $X Y$ plane angle' were measured relative to the $X Y$ plane for each lacuna in each wedge. 'Distance from XY plane' describes the Euclidean distance of each lacuna's center to the $X Y$ plane, with positive values in the perichondral direction and negative values in the chondral direction. ' $X Y$ plane angle' describes the orientation of the lacuna's major axis within the $X Y$ plane, with a $0^{\circ}$ orientation indicating alignment with the wedge's $X$ axis. Due to the radial symmetry of tesserae and since we are interested in 
understanding the degree of alignment of lacunae toward the neighboring tessera (i.e. $0^{\circ} \mathrm{XY}$ plane angle), we took the absolute value of these angular deviations from the $X$ axis (i.e. $+5^{\circ}$ and $-5^{\circ}$ are considered the same). Additionally, the Euclidean distances of lacunae from the tesseral center were measured within the $X Y$ plane ('Distance from $Z$ axis') and the angular deviation of each lacuna relative to the perichondral-chondral axis ( $Z$ axis angle), where $0^{\circ}$ represented orientation 'upward' toward the perichondrium and $180^{\circ}$ orientation 'downward' toward the chondral edge of the tessera. This angle was derived from the covariance analysis of the lacuna volumes and, if necessary, converted to values between 0 and $180^{\circ}$ (i.e. an angle of $185^{\circ}$ is equivalent to a $5^{\circ}$ angle relative to the $Z$ axis). In this way, the lacunae were always in the same coordinate space and could always be understood as pointing away from the $Z$ axis.

\subsubsection{Regional analysis}

Local variation in the cross-sectional shape of tesserae lacunae has been observed by several authors $[13,17,27]$. In particular, flatter lacunae are often noted in the perichondral region and rounder lacunae are generally found in the central region of tesserae. These differences have, however, never been quantified or examined in 3D. To determine whether quantitative aspects of shape and size are diagnostic features of lacunae from specific tesseral regions, we coded all lacunae according to their location within tesserae, based on previous anatomical studies and preliminary observations of our data. Lacunae were coded to regions with a custom Matlab script, with regions defined as follows:

Center region: an ellipsoid $50 \mu \mathrm{m}$ wide and deep and $30 \mu \mathrm{m}$ tall, centered at the tesseral centroid.

Perichondral region: a truncated, inverted, cone-shaped region above the center region. The perichondral region was first established as an upside-down cone with vertex at the tesseral centroid, the $Z$ axis as the cone axis, and a cone angle of $138^{\circ}$ (measured from published and unpublished histological and SEM images). The center region was then subtracted from the perichondral cone (i.e. lacunae in the cone tip belonged to the center, but lacunae in the base belonged to the perichondral region).

Chondral region: a truncated, cone-shaped region below the center region, established as with the perichondral region, but with the cone rotated $180^{\circ}$ (i.e. apex oriented upward). Similar to the perichondral region, the center region was subtracted from the chondral cone, such that lacunae in the cone tip belonged to the center, but lacunae in the base belonged to the chondral region.

Radial region: the remaining unclassified portion of the tesserae, the region peripheral to the center, but not within the perichondral or chondral regions.

\subsubsection{Statistical analyses}

Quantitative comparisons of group mean values for lacunae variables were calculated using a combination of ANOVA and PERMANOVA models. For all ANOVA analyses, the assumption of homogeneity of variance between response variables was evaluated using the F-test (whenever sample size allowed) or a comparison of Bartlett's test and Levene's test. Histograms were plotted to evaluate the assumption of normality. When variance differed significantly, Welch's ANOVAs were used instead of typical (Fisher) ANOVAs [28]. If normality and variance 
assumptions were grossly violated, PERMANOVA with multivariate homogeneity of group dispersion tests were calculated [29]. Bonferroni corrections were used when low sample size necessitated multiple comparisons. Power analyses were conducted when significant differences between or among group means were not detected. Mean lacuna density values between animals and among tesserae within animals were compared using one-way ANOVAs. Mean lacuna major axis length, anisotropy, elongation, flatness, and volume values were compared for animals, animals:tesserae, and animals:tesserae:wedges using PERMANOVA. Mean values of anisotropy, elongation, flatness, and volume were additionally compared between pore-adjacent and normal (non-pore adjacent) wedges and among tesseral regions (center, perichondral, chondral, radial) using one-way ANOVAs. Tukey post hoc tests were used to localize significant differences among group means. Correlations among lacunae density and volume for tesserae and for pore and non-pore wedges were examined via Pearson's correlation analysis. Calculations for these and all subsequent analyses were performed using R statistical software v. 3.6.2 [30].

To test whether lacunar shape and size metrics support the regional codings described in section 2.3.2 above, linear discriminant analysis (LDA) [31] was used to examine morphological differences in lacunae among designated tesserae regions (center, chondral, perichondral, radial). The reliability of regional assignments (i.e., group membership) within tesserae -in other words, the probability of assigning a lacuna to its correct region based on a simultaneous consideration of the four examined variables (volume, anisotropy, elongation and flatness) was determined by computing the overall correct classification rate and the predicted group membership rates among regions. A biplot of the first two canonical axes was generated and used in conjunction with canonical structure correlations (i.e., Pearson product-moment bivariate correlations) and group means for interpretation. These canonical structure correlations indicate the strength and nature (positive or negative) of the relationship between each discriminating variable (anisotropy, elongation, flatness, volume) and the canonical scores associated with each axis [32]. 

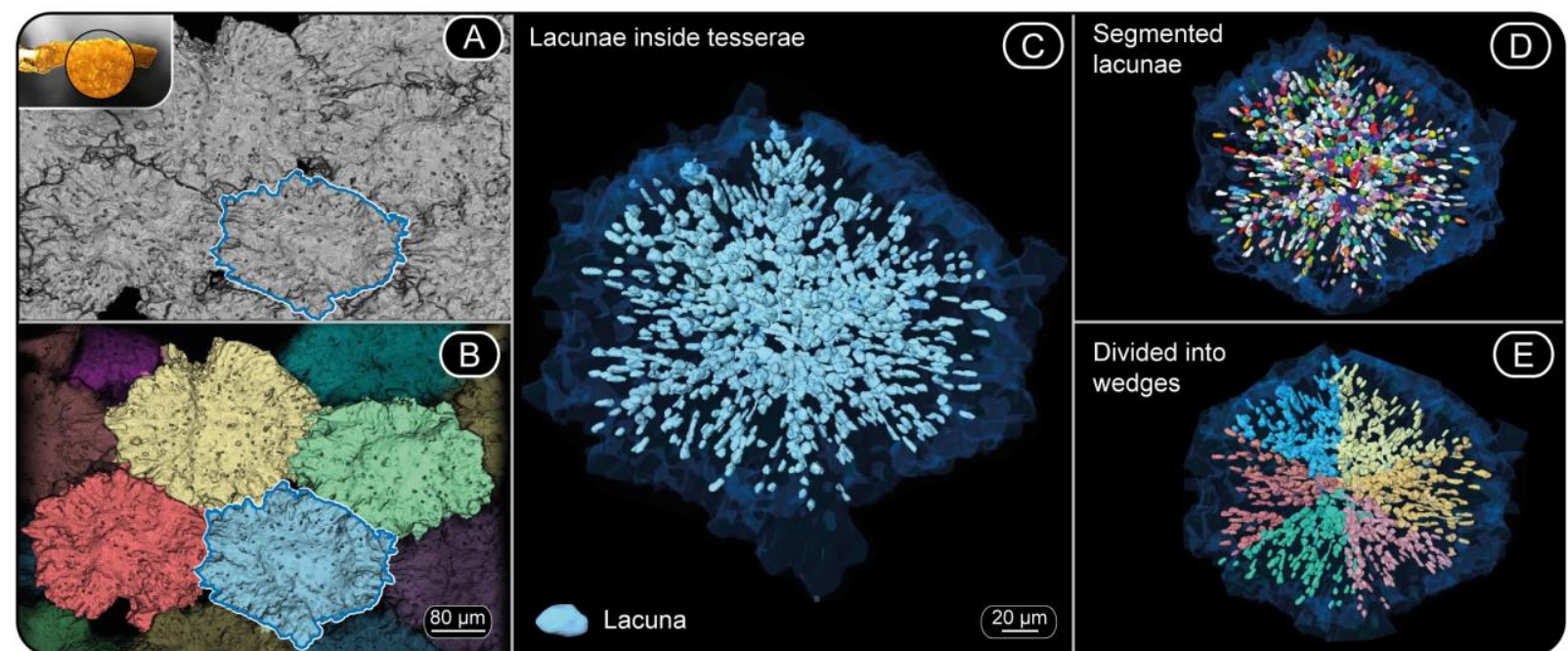

Figure 2. Workflow for lacunae segmentation and quantification. A) SR- $\mu \mathrm{CT}$ scan of the tesserae layer. Several individual tesserae are visible, illustrating the tight packing of tesserae and the challenge of separating individual tesserae from each other. The tile outlined in blue is used as an example throughout this figure. A pseudo-colored photograph of the original sample is shown in the inset image to the upper left, with a zoom inset showing several individual tesserae. B) Segmentation of the individual tesserae to be studied. C) Segmentation of the lacunae (light blue) inside the blue tessera indicated in A and B. D) Segmentation of lacunae into individual objects, where each color corresponds to an individual lacuna. E) Division of the lacunae into wedges, with their lacunae represented in unique colors. Each wedge is defined according to the tessera's contact zone in contact with the neighboring tessera (see Fig. 3). 


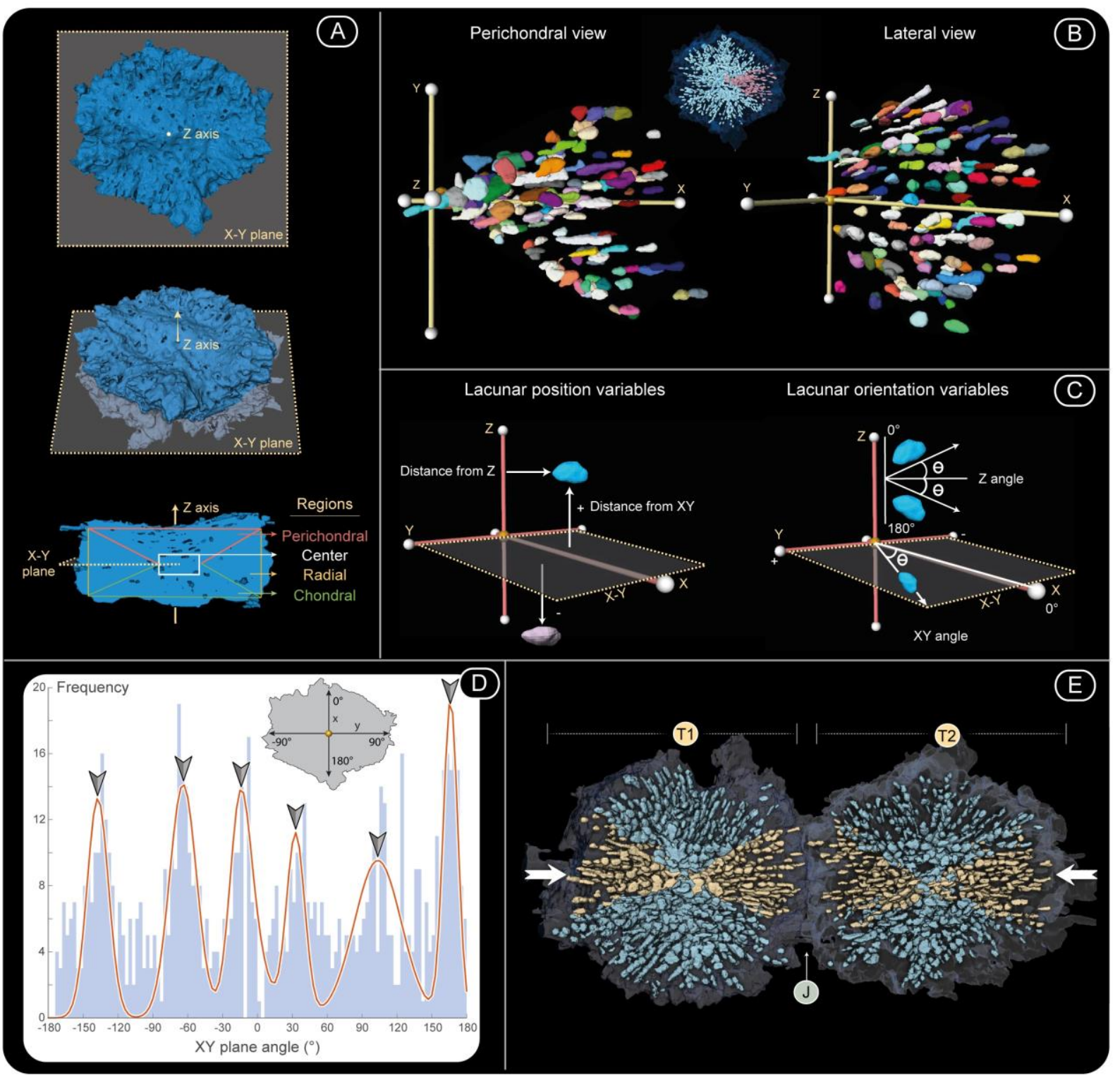

Figure 3. Analysis coordinate system and description of orientation, position variables and wedge division. A) Axes used to divide tesserae for analysis, where the $X Y$ plane is oriented parallel to the plane that best approximated the tessera (i.e. the plane that minimizes the sum of squared distances for all voxels), and the $Z$ axis runs through the center of the tessera in the vertical direction. The tesserae regions used for lacunae classification-perichondral, center, radial, chondral-are shown in the tessera cross section at the bottom. B) Position of the axes in one tessera wedge. The center of the wedge is the center of the tessera, thus all wedges from one tessera have the same $Z$ axis. The $X Y$ plane is that established for each tessera (i.e. all wedges share the same $X Y$ plane), but in each wedge, the $X$ axis is oriented towards the center of the neighboring tessera. C) Visual representation of the variables for lacunae position (left) and orientation (right), described in Table 1. See text for descriptions of definition of planes and tessera center. D) Variation of lacuna major axis angle within the XY plane for all lacunae in a tessera. The icon illustrates relevant $X Y$ plane angles. The red line depicts a Gaussian Mixture Model curve fit (see Methods) with the peaks (arrowheads) corresponding to groups of lacunae oriented toward 
the contact zones with tesserae neighbors, indicating the relevance of wedges as a dividing subunit for tesserae. E) Orientation of lacunae (yellow) orientation in corresponding wedges of two tesserae (T1, T2), illustrating co-alignment of lacunae between adjacent tesserae and longer range patterning of the tissue.

\begin{tabular}{|c|c|c|}
\hline Variable type & Variable (units) & Description \\
\hline \multirow{2}{*}{$\begin{array}{l}\text { Lacunar } \\
\text { population }\end{array}$} & Abundance $(\mathrm{N})$ & Number of lacunae per tessera \\
\hline & Density $\left(\mathrm{N} / \mathrm{mm}^{3}\right)$ & Number of lacunae per unit tissue volume \\
\hline \multirow{5}{*}{$\begin{array}{l}\text { Lacunar } \\
\text { morphometric } \\
\text { variables }\end{array}$} & Volume $\left(\mu \mathrm{m}^{3}\right)$ & Volume of lacunae \\
\hline & Dimensions $(\mu \mathrm{m})$ & Length of lacunar primary, secondary and tertiary axes \\
\hline & Flatness & $\begin{array}{l}\text { Ratio of smallest to medium EV: EV3 / EV2 } \\
\text { Flatter (e.g. frisbee-shaped) lacunae have lower } \\
\text { values, perfect spheres }=1.0\end{array}$ \\
\hline & Elongation & $\begin{array}{l}\text { Ratio of medium to largest EV: EV2 / EV1 } \\
\text { More elongate (e.g. cigar-shaped) lacunae have lower } \\
\text { values, perfect spheres }=1.0\end{array}$ \\
\hline & Anisotropy & $\begin{array}{l}\text { One minus the ratio of smallest to largest EV: } 1 \text { - EV3 / } \\
\text { EV1 } \\
\text { Lacunae with similar major and minor axes are more } \\
\text { isotropic (i.e. more spherical = 0) with lower anisotropy. } \\
\text { Lacunae with dissimilar major and minor axes have } \\
\text { higher anisotropy }\end{array}$ \\
\hline \multirow[t]{2}{*}{$\begin{array}{l}\text { Lacunar } \\
\text { position }\end{array}$} & Distance from XY plane $(\mu \mathrm{m})$ & $\begin{array}{l}\text { Distance of lacunae from the horizontal plane } \\
\text { Describes perichondral-chondral position }\end{array}$ \\
\hline & Distance from $Z$ axis $(\mu \mathrm{m})$ & $\begin{array}{l}\text { Distance of lacunae from vertical axis } \\
\text { Describes position relative to the tessera center }\end{array}$ \\
\hline \multirow[t]{2}{*}{$\begin{array}{l}\text { Lacunar } \\
\quad \text { orientation }\end{array}$} & $X Y$ plane angle $(\theta)$ & $\begin{array}{l}\text { Angular deviation }\left( \pm 90^{\circ}\right) \text { of lacunae from } X \text { axis } \\
\text { Describes lacuna alignment toward neighboring } \\
\text { tessera }\end{array}$ \\
\hline & $Z$ axis angle $(\theta)$ & $\begin{array}{l}\text { Angular deviation of lacunae from vertical axis } \\
\text { Describes lacuna alignment toward tessera's } \\
\text { perichondral }\left(0^{\circ}\right) \text { or chondral }\left(180^{\circ}\right) \text { edges }\end{array}$ \\
\hline
\end{tabular}

Table 1. Variables used to describe chondrocyte lacunae shape and arrangements within tesserae. Variables describing lacunar shape (flatness, elongation, anisotropy) were calculated as ratios of eigenvalues $(E V)$ of each lacuna's covariance matrix, which is built from the coordinates of all voxels of the lacuna. The eigenvalues are sorted such that EV1 is the largest and EV3 the smallest (EV1>EV2>EV3). Taken together, the three shape variables describe the 3D symmetry of lacunae. 


\section{Results}

3.1 General lacuna morphology and arrangement. In our analyses of nine individual tesserae, a total of 12,586 cell lacunae were isolated and their morphologies quantified. Lacunae were spheroidal (Tables 2,3), but variable in shape according to their locations within tesserae (see below). Lacunae were also quite variable in their dimensions, having average $(+/-$ sd) major, middle and minor axis lengths of $17.3 \pm 5.6,11.4 \pm 2.8$ and $8.27 \pm 2.0 \mu \mathrm{m}$, respectively. Lacuna volumes varied considerably, being on average $649.1 \pm 382.6 \mu^{3}$. Further general morphometric characteristics of lacunae are summarized in Table 2.

Lacunae were not distributed randomly within tesserae, but rather appeared to radiate outward from the tesseral center (e.g. Fig. 3D). This arrangement was particularly visible in more peripheral lacunae (i.e. lacunae in the 'radial' region) and in perichondral (top) views of the lacunar arrays (Fig. 3D, 5, 7A). This radiating pattern was visibly disrupted in two locations. Firstly, where tesserae bordered pores and the pores appeared to cut into the margin of the tesserae (Fig. 1C, 4A), lacunae exhibited an altered arrangement (see below). Additionally, some $3 d$ zones in tesserae lacked lacunae entirely (e.g. Fig. 6A, 7A). These areas correlated with the presence of tesseral 'spokes', acellular, high mineral-density features radiating from contact points between tesserae [13,22].

3.2 Tesserae lacunar densities. The number of lacunae per tessera varied from 664 to 2,600, with the average lacunar density being 96,788 $\pm 18,083$ lacunae $/ \mathrm{mm}^{3}$ (Fig. 4B). Lacunar densities were compared statistically between animals, among tesserae and among wedges as follows:

Animals. Group variance did not differ significantly between the two individual stingrays $(F=$ 5.52, num df $=4$, denom $\mathrm{df}=3, P=0.192$ ) and one-way ANOVA results indicated, with high power $(0.999$ at $P<0.05)$, that mean lacuna density did not differ significantly between stingrays ( $\mathrm{df}=1, \mathrm{~F}=2.57, P=0.153$ ), allowing us to lump animals to test density difference among tesserae.

Tesserae. Barlett's and Levene's tests differed, but an exploration of the data showed extreme and uneven variance in mean density among tesserae. A one-way Welch's ANOVA indicated significant differences in mean density among tesserae $(F=3.92$, num $\mathrm{df}=8.00$, denom $\mathrm{df}=$ 17.44, $P=0.008$, Bonferroni adjusted significant $P<0.025)$. Lacunar densities varied $1.75 x$ across tesserae examined, ranging from 74,547 to 129,818 lacunae $/ \mathrm{mm}^{3}$ in tesserae and increasing with tesseral volume (Fig. 4B; $r=0.60 ; P=0.061$ ).

Wedges. Lacunar densities showed a >3-fold variation across wedges, from 56,914 to 197,692 lacunae $/ \mathrm{mm}^{3}$. Lacunar density in non-pore wedges exhibited an increase with wedge volume $(r$ $=0.20 ; P=0.162)$, whereas in pore wedges a decrease with wedge volume was suggested $(r=$ $-0.61 ; P=0.384$ ), although both trends were non-significant (Fig. 4C). Statistical comparison of 
lacunar densities among the 52 unique wedges was impossible, due to each wedge having just one measured density value. Comparison of lacunar densities between normal wedges and the few pore-adjacent wedges $(n=4)$, however, showed that group variance did not differ significantly between these wedge types $(F=0.59$, num $d f=3$, denom $d f=47, P=0.761)$. Subsequent one-way ANOVA results indicated that the mean lacuna density of pore-adjacent wedges was significantly greater than those of non-pore adjacent wedges $(\mathrm{F}=61.62, \mathrm{df}=1, P<$ 0.001) (Fig.4C; see below).

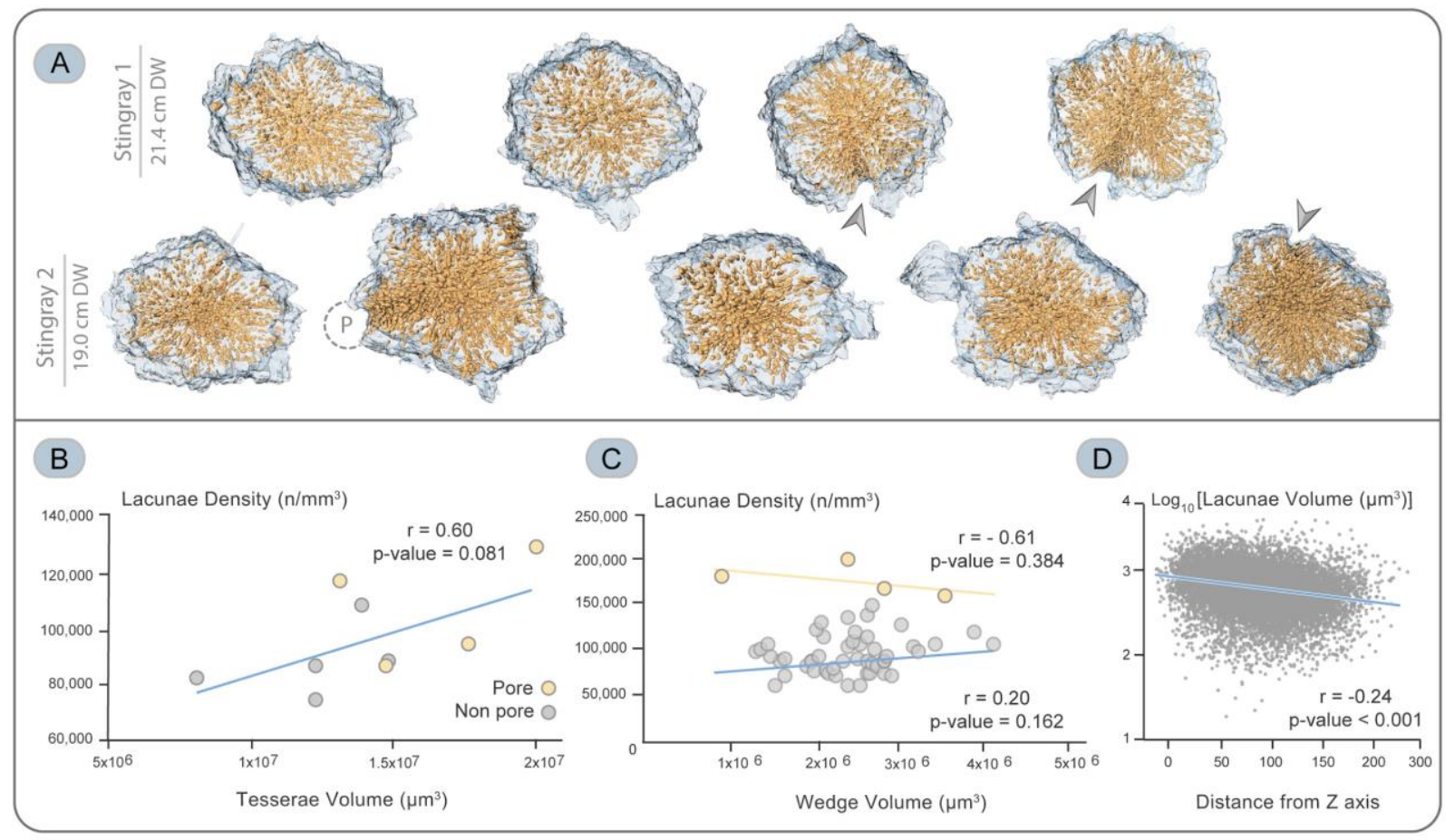

Figure 4. Tesserae analyzed and the effect of pores on lacunar density. A) All tesserae analyzed from two stingrays ( $U$. halleri), showing the lacunae (orange) inside the mineralized matrix (light gray). Note the general pattern of lacunae radiating outward from the tesseral centers. Some of the tesserae bordered pores $(\mathrm{P})$, located at the intersection point of several tesserae and forming a depression in the mineralized matrix (arrowheads; see also Fig. 1C). Scatter plots and results of Pearson's correlations relating B) lacuna density and tesserae volume, C) lacuna density and wedge volume, and D) lacuna volume and distance from the $Z$ axis (tesseral center). The latter reflects the comparatively large volume of central lacunae relative to more peripheral ones.

3.3 Lacuna shape and tesserae regions. For volume, anisotropy, elongation and flatness, all comparisons of group means (Animal, Animal:Tesserae, Animal:Tesserae:Wedge) were highly significant ( $p<0.001$; Table S1), indicating that all variables differed between animals, among tesserae within an animal's sample, and among wedges within tesserae. The investigated regions within tesserae - center, perichondral, chondral and radial- exhibited a variety of significant differences in their mean volume, flatness, elongation and anisotropy. All comparisons of variance were highly significant $(P<0.001$; Table $\mathrm{S} 1)$. Average values for lacuna 
shape are discussed by region below and summarized in Table 3, and the average regional cell geometries are shown in Figure 5.

Flatness. Perichondral lacunae were flattest $(\bar{x}=0.44 \pm 0.21)$, followed by central $(\bar{x}=0.49 \pm$ $0.20)$, radial $(\bar{x}=0.55 \pm 0.18)$ and chondral lacunae $(\bar{x}=0.60 \pm 0.19)$, which were significantly less flat than the other groups (t-value $=25.621, P<0.001$ ). Perichondral cells as a group (e.g. when volume-rendered together; Fig. 5) typically exhibited an inverted pyramid formation in the tessera.

Anisotropy. All regions presented significant differences in anisotropy $(\mathrm{F}=491.34, \mathrm{df}=3.00, P<$ 0.001 ), with the exception of perichondral and central lacunae. Chondral lacunae presented the lowest anisotropy (i.e. were more spherical; $\bar{x}=0.69 \pm 0.16$ ), significantly different from that of other regions (t-value $=25.621, P<0.001)$, followed by radial $(\bar{x}=0.76 \pm 0.14)$, perichondral $(\bar{x}$ $=0.83 \pm 0.13)$ and central regions $(\bar{x}=0.82 \pm 0.11)$, which did not differ significantly from one another.

Elongation. All regions presented significant differences in elongation $(\mathrm{F}=175.41$, $\mathrm{df}=3.00, P<$ 0.001 ), with the exception of perichondral and central lacunae, which were not significantly different. Central $(\bar{x}=0.38 \pm 0.22)$ and perichondral lacunae $(\bar{x}=0.39 \pm 0.21)$ were the most elongated, followed by radial $(\bar{x}=0.43 \pm 0.22)$ and chondral lacunae $(\bar{x}=0.50 \pm 0.20)$.

Volume. Chondral, central, radial and perichondral regions differed significantly in lacuna volume $(\mathrm{F}=80.095, \mathrm{df}=3.00, P<0.001)$. Central lacunae presented the highest volume, being on average 1.3x larger than chondral cells, 1.5x larger than perichondral cells and 1.6x larger than radial cells (Fig. 5). This difference in volume among regions is further illustrated by the significant decrease (Fig. 4D, $r=0.24, P<0.001$ ) in lacunar volume with increasing $Z$ axis distance (i.e. moving from the center region outward into the radial region). Local density variation was not quantified in our analyses, but slices passing through the center could be easily identified based on the visual appearance of central lacunae, which formed high density clusters of visibly larger lacunae in a 'bunch of grapes' morphology (Fig. 7).

Despite these average morphological trends for the individual regions, due to the large variation in lacuna shape, we found little overall distinction among regions. The variable loadings and the LDA biplot are shown in Fig. S1; some separation of tesseral regions were evident, especially on Axis 1, which separated lacunae with high values of flatness and elongation from those with high values of anisotropy. Axis 2 separated lacunae with high values of flatness from those with large volumes. Axis 1 is, however, much more relevant than axis 2, explaining $84.3 \%$ vs. $13.7 \%$, respectively. Region reassignment success for lacunae was moderate (50.9\% overall), most effective for radial lacunae $(70.3 \%)$, then perichondral $(41.8 \%)$ and chondral lacunae $(30.6 \%)$, with center lacunae having a $0 \%$ reassignment success. The observed poor reassignment was due to the large overall variation in lacuna morphology and, in the case of central lacunae, compounded by the comparatively small sample size $(n=82$ central lacunae, in comparison with $>3,200$ lacunae per each of the other regions). 


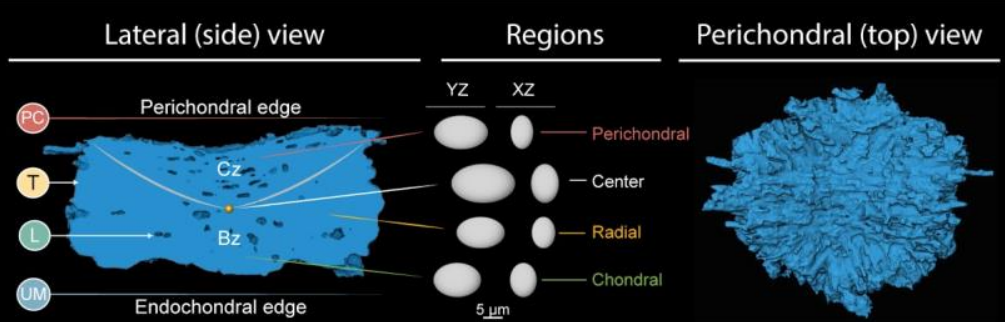

Perichondral /'cap' lacunae

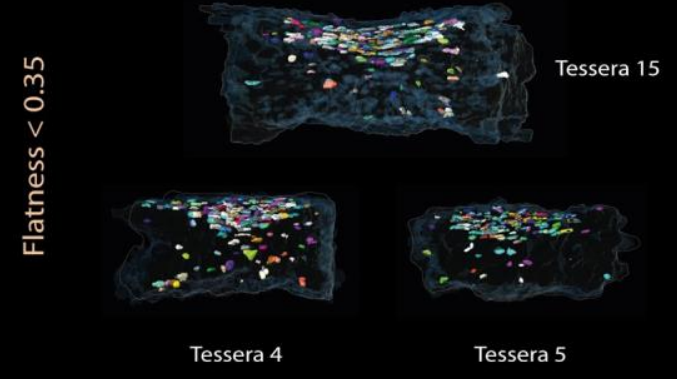

Radial lacunae
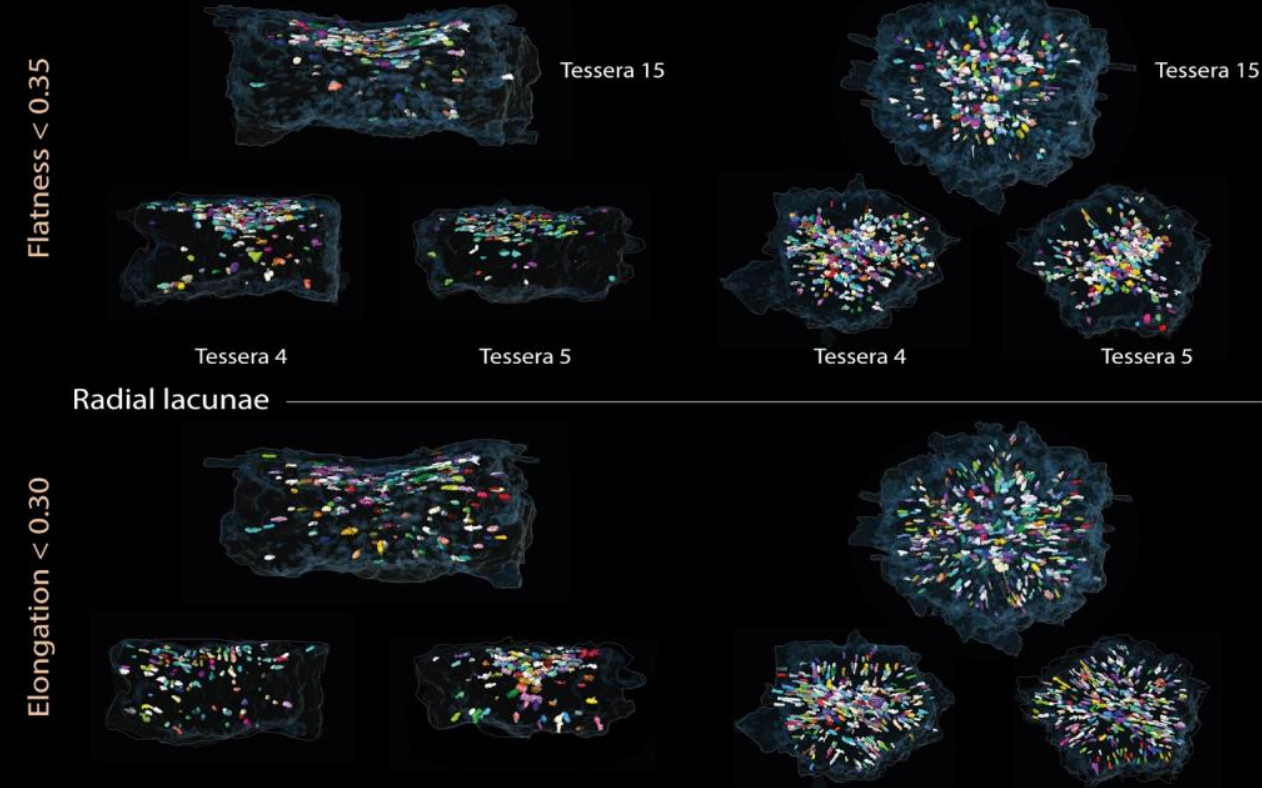

Chondral / 'body' lacunae

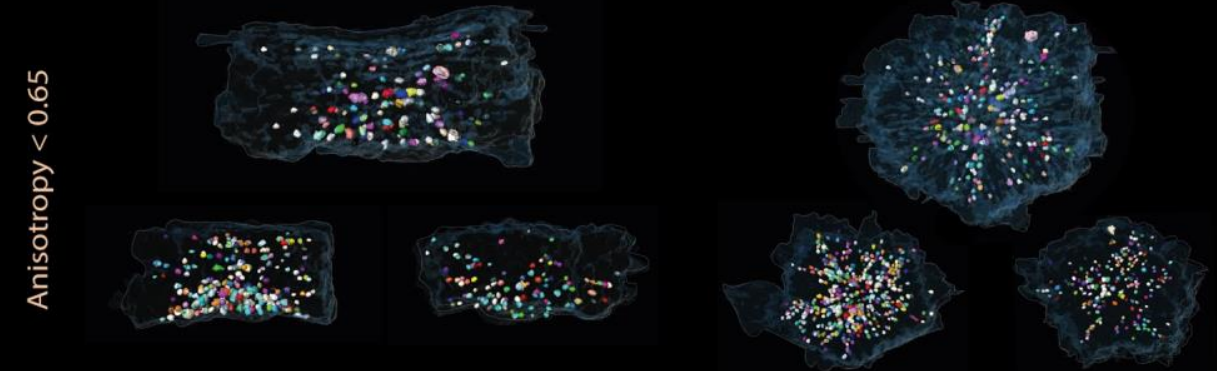

Center lacunae
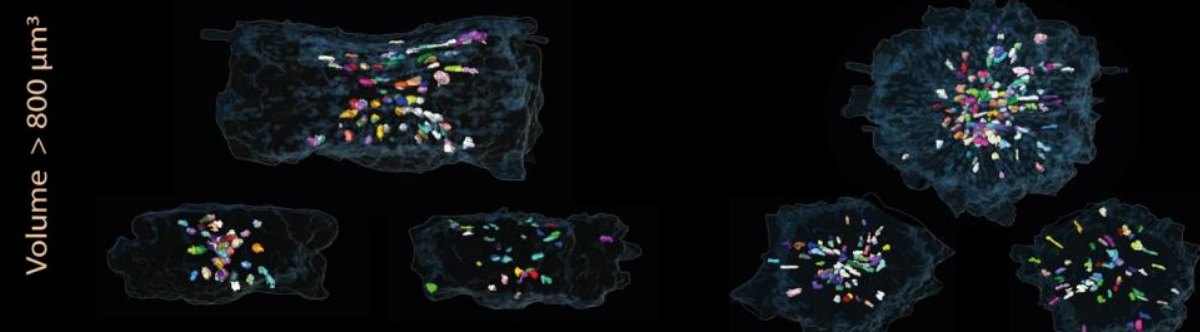
Figure 5. Zonal differentiation in tesserae based on the shape, volume and distribution of lacunae. The scheme in the top row of the figure shows 1) left and right: the different tesserae views used throughout the figure: lateral/side and perichondral/top views of a tessera (in the left and right columns of images, respectively). 2) middle: Rendering of the mean lacuna shape for each region, shown from $Y Z$ and $X Z$ orientations. The remainder of the figure is organized into rows defining lacunar region types (e.g. 'Perichondral lacunae'), illustrating those lacunae in 3D renderings from three exemplar, non-pore tesserae (Tesserae \#4, 5, 15; tessera 15 is also the tessera shown at the top of the figure). For each region, a threshold value for a single variable is used based on observed ranges (e.g. flatness $<0.35$ for perichondral / "cap" lacunae). This shows the tendency of certain lacunar morphologies in certain regions (e.g. flatter perichondral lacunae in the cap zone in contrast with more spherical chondral cells in the body zone). Tesseral zones are described in detail in the text. Lacunae (L), Perichondrium (PC), Tesserae (T), Unmineralized Matrix (UM).

Pore- vs. non-pore wedges. In wedges not bordering pores, lacunae were oriented strongly toward the neighboring tessera (Fig. 3D, 5, 6B-C). Lacunae in these wedges tended to be horizontally oriented throughout the tessera ( $Z$ axis angle: $88.2 \pm 21.1^{\circ}$, where $90^{\circ}$ is perfectly horizontal), representing the organization of lacunae into layers stacked in the perichondralchondral (Z) direction (Fig. 5).

In contrast, in pore-adjacent wedges, lacunae were more densely packed (see '3.2 Tesserae lacunar densities' above) and were far less aligned to the neighboring tessera in the XY plane (Fig. 6B-D). Lacunae in pore-wedges exhibited a similar mean orientation relative to the $Z$ axis as non-pore wedges, but with more orientational variation ( $Z$ axis angle: $88.1 \pm 38.6^{\circ}$ ), often being more vertically oriented with increasing distance from the tesseral center (i.e. closer to pores; note the secondary peak at low $Z$ axis angle in Fig. 6C-D, 7C). As a result, renderings of the lacunae in pore wedges often looked like wax dripping off of a surface, with elongate radial lacunae cascading downward toward the chondral edge (Fig. 7C). As mentioned above, pores appeared to carve into the joint edges of pore-adjacent wedges, leaving a marginal, semicircular gap in the tessera and the lacunar array (Fig. 4A). Pore-wedges were therefore easily identified, both in 2D slices and 3D renderings (Fig. 6D, 7C).

Mean values were significantly different for pore and non-pore wedges with regard to anisotropy $(\mathrm{F}=29.752$, num $\mathrm{df}=1.0$, denom $\mathrm{df}=2334.3, P<0.001)$, flatness $(\mathrm{F}=50.78$, num $\mathrm{df}=1.0, P<$ $0.001)$, and volume $(\mathrm{F}=107.92$, num $\mathrm{df}=1.0$, denom $\mathrm{df}=2170.4, P<0.001)$, with pore wedges having larger, flatter lacunae (with higher anisotropy and volume and lower flatness values). Mean values for elongation did not differ significantly between pore and non-pore wedges $(F=$ 0.737 , num $\mathrm{df}=1.0, P=0.391$, power $=0.343$ at $P<0.05$ ). 


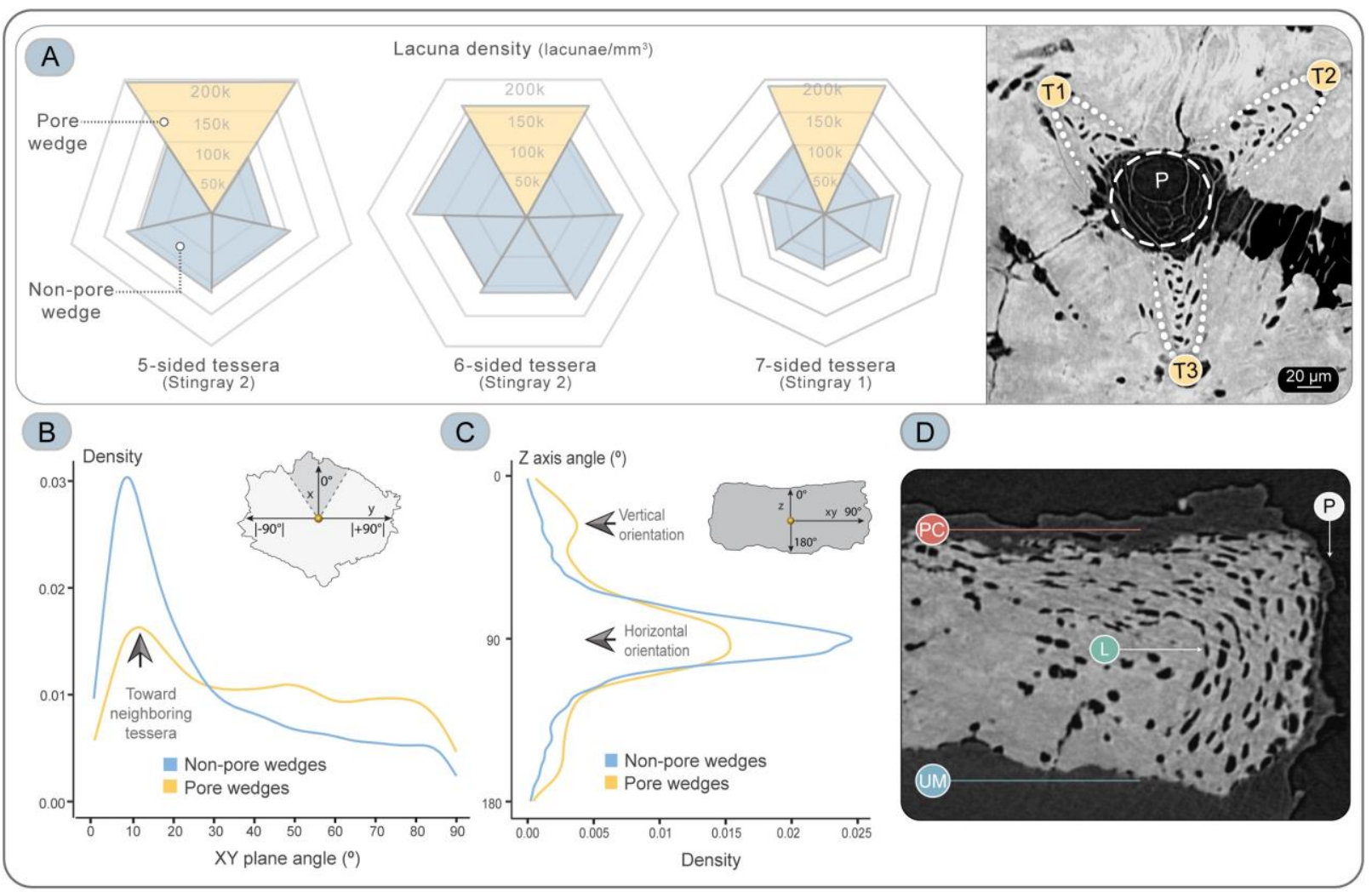

Figure 6. Effect of pores on lacuna arrangements and densities in tesserae wedges. A) Lacunar density values for each wedge of three tesserae in contact with pores. Lacunar densities in wedges in contact with pores (yellow) are up to $3 x$ higher than those in non-pore wedges (blue). In the SR- $\mu$ CT image on the right, note the position of the pore relative to the three tesserae (T1, T2, T3) and the distinct arrangements and densities of lacunae in the regions adjacent to the pore. Plots of B) XY plane angle and C) $Z$ axis angle for all wedges analyzed. Note the difference in lacunae orientation between wedges with and without pores in both plots, the strong neighbor-orientation of lacunae in non-pore wedges in $B$ and the shift to a vertical orientation in pore wedge lacunae in C. D) CT-scan image showing variation of lacunae orientation for wedges in contact with pores. Intertesseral Joint (J), Lacunae (L), Perichondrium $(\mathrm{PC})$, Pore (P), Tesserae (T), Unmineralized Matrix (UM).

Canaliculi. Although tesserae canaliculi were not a focus of the current study, they were often clearly visible in our SR- $\mu$ CT scan data (Fig. 7A) and we noted several morphological features not previously described [18] that bear brief mention. We observed large variation in canalicular morphology, diameter, orientation and position, but they could broadly be broken into two primary categories. Firstly, thinner canalicular passages ( 5-15 $\mu \mathrm{m}$ long and $\sim 1-3 \mu \mathrm{m}$ diameter) were regularly seen linking radial lacunae into horizontal 'strings' (or vertical 'strings' in porewedges) (Fig. 6B, 7); this morphology is consistent with that previously described for tesserae [18]. Secondly, we also observed larger canalicular passages $(\sim 10 \mu \mathrm{m}$ long and $\sim 10-15 \mu \mathrm{m}$ diameter) linking center cells in both horizontal and vertical directions. These passages were so thick as to often challenge the separation of adjacent center cells in data analysis, resulting in the 'bunch of grapes' morphology described above (Fig. 7A, D). 


\begin{tabular}{|c|c|c|c|c|c|}
\hline Structure & $\begin{array}{l}\text { Morphometric } \\
\text { parameters }\end{array}$ & 1st Quartile & $\bar{x}$ & 3rd Quartile & sd \\
\hline \multirow{2}{*}{ Tesserae } & Volume $\left(\mu \mathrm{m}^{3}\right)$ & $1.23 \times 10^{7}$ & $1.41 \times 10^{7}$ & $1.39 \times 10^{7}$ & $3.41 \times 10^{6}$ \\
\hline & $\begin{array}{c}\text { Number of lacunae } \\
\text { per tessera }\end{array}$ & 1072 & 1398 & 1532 & 554.04 \\
\hline \multirow{5}{*}{ Lacunae } & Density $\left(\mathrm{n} / \mathrm{mm}^{3}\right)$ & $77,829.00$ & $96,787.90$ & $110,907.23$ & $18,083.10$ \\
\hline & Volume $\left(\mu \mathrm{m}^{3}\right)$ & 389.22 & 649.12 & 813.39 & 382.60 \\
\hline & $\begin{array}{l}\text { Major axis length } \\
(\mu \mathrm{m})\end{array}$ & 13.45 & 17.33 & 20.088 & 5.62 \\
\hline & $\begin{array}{l}\text { Middle axis length } \\
\qquad(\mu \mathrm{m})\end{array}$ & 9.52 & 11.38 & 12.90 & 2.80 \\
\hline & $\begin{array}{l}\text { Minor axis length } \\
(\mu \mathrm{m})\end{array}$ & 6.84 & 8.27 & 9.50 & 2.01 \\
\hline
\end{tabular}

Table 2. Morphological parameters of cell lacunae in the tesserae layer of the stingray Urobatis halleri.

\begin{tabular}{ccccc}
\hline Region & $\overline{\mathrm{x}}$ Flatness $\pm \mathrm{sd}$ & $\overline{\mathrm{x}}$ Elongation $\pm \mathrm{sd}$ & $\overline{\mathrm{x}}$ Anisotropy $\pm \mathrm{sd}$ & $\overline{\mathrm{x}}$ Volume $\left(\mu \mathrm{m}^{3}\right) \pm \mathrm{sd}$ \\
\hline Center & $0.49 \pm 0.21$ & $0.38 \pm 0.22$ & $0.82 \pm 0.11$ & $957.62 \pm 462.90$ \\
Chondral & $0.60 \pm 0.19$ & $0.50 \pm 0.21$ & $0.69 \pm 0.16$ & $732.18 \pm 424.50$ \\
& & & & \\
Perichondral & $0.44 \pm 0.21$ & $0.39 \pm 0.22$ & $0.83 \pm 0.13$ & $641.22 \pm 372.09$ \\
& & & & \\
Radial & $0.55 \pm 0.19$ & $0.43 \pm 0.22$ & $0.76 \pm 0.14$ & $604.82 \pm 364.82$ \\
\hline
\end{tabular}

Table 3. Mean values of the lacuna morphometric variables measured for each tesseral region 


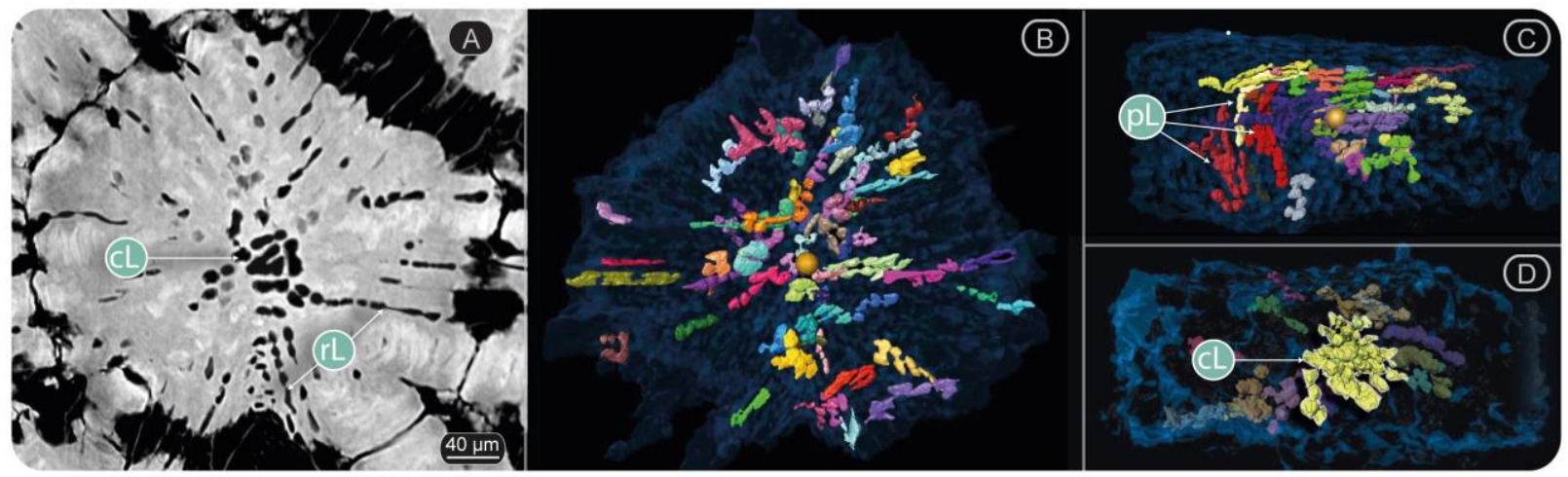

Figure 7. Lacunar connections (canaliculi) in tesserae. A) Projection image of several SR $\mu$ CT slices of Urobatis halleri tesserae, showing rows of lacunae joined together by short passages (canaliculi) in the radial zones and clustered lacunae concentrated in the center of the tessera. B) Perichondral (top) view of a tessera showing a large variety of lacunae connected in series and radiating in the $X Y$ plane in multiple directions from the center of the tessera. Surrounding individual lacunae have been filtered from this image for clarity. C) Strings of radial lacunae adjacent to a pore turning toward the chondral direction (see Fig. 6D). D) Clustered central lacunae joined together in a 'bunch of grapes' morphology. Renderings in B-D are prior to the Contour Tree segmentation step in the 'Segmentation of lacunae' process described in [25]. Central lacunae (cL); pore lacunae ( $\mathrm{pL})$; radial lacunae $(\mathrm{rL})$; spokes $(\mathrm{Sp})$.
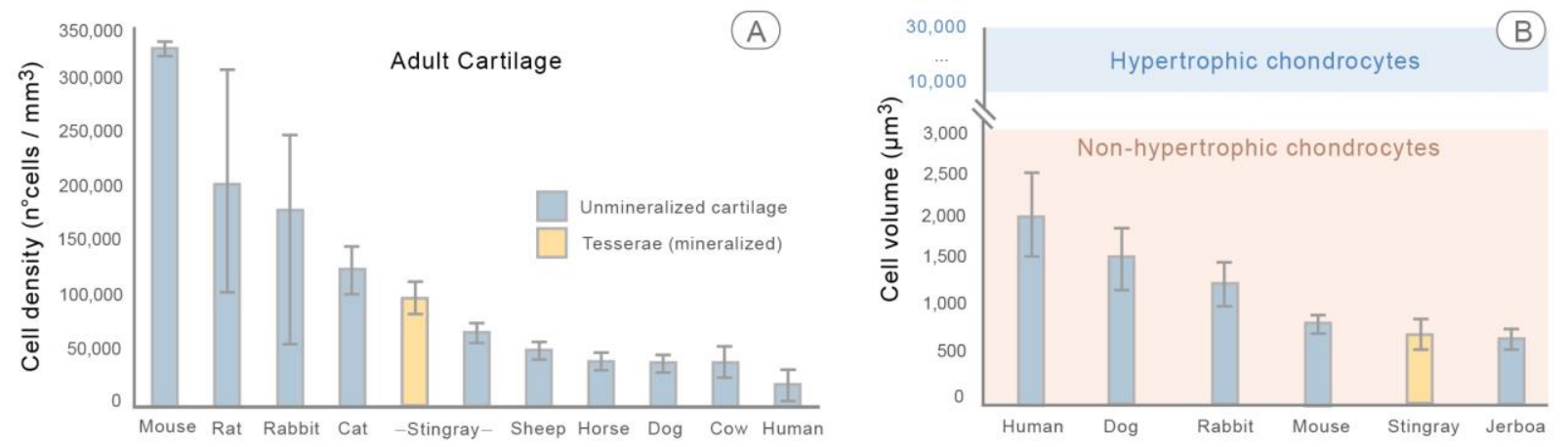

Figure 8. Chondrocyte density and volume variation across vertebrate cartilages. A) Chondrocyte density variation in adult articular cartilage across different vertebrates, including values for Urobatis halleri tesserae (from the current study; yellow boxes) and unmineralized cartilage [12]. B) Volume of non-hypertrophic chondrocytes in adult articular cartilage (human, dog, rabbit, mouse and stingray) and in the resting zone of the growth plate for jerboa. The volume of hypertrophic chondrocytes ( $>10 \mathrm{x}$ higher) is included for reference at the top of the figure (blue horizontal swath). Cartilage data for other species from: mouse [33]; rat [33]; rabbit [33-36]; cat [33,37]; stingray [12]; sheep [33]; horse [37]; dog [33,38]; cow [33,37,39]; human [6,40-42]; jerboa [43].

\section{Discussion}

As John Currey contended: "Calcified cartilage appears in various places in vertebrates but two places are of particular importance: at the ends of growing long bones, and in the general 
skeleton of many sharks" [1]. The former tissue is far more investigated than the latter. In fact, studies have only recently demonstrated that elasmobranch tesserae are not simply calcified cartilage (i.e. Type II-collagen based) and may not rely on the same mechanisms mammalian skeletons use for mineralization [17,44-46]. Our study provides the first window into the life of cells within tesserae, quantifying aspects of the cell lacunae and thereby allowing insights into tissue growth dynamics, potential roles of the cells, and the ways in which this system combines features of more familiar (i.e. mammalian) models of bone and cartilage. In particular, in the following discussion, we make comparisons predominantly to mammalian hyaline cartilage, an important and relevant benchmark due to the rich literature on its structure and growth and its gross histological similarity to shark and ray unmineralized cartilage $[12,17,47,48]$.

Mineralization and growth. Our lacunar morphometric data, particularly when contextualized next to information on mammalian chondrocytes, provide a variety of useful signposts for decoding cellular involvement in mineralization in the elasmobranch skeleton (Fig. 8). In mammals, mineralized cartilage is not predominant in the skeleton. It is found as a thin, persistent layer, for example, beneath the articular cartilage of long bones, as a transitional layer beneath long bone growth plates, and as a pathologic tissue $[1,2,49,50]$. In contrast, in elasmobranchs, true mineralized cartilage (e.g. the Type II-collagen matrix of the tesseral 'body' zone; [17]) is a prevalent, permanent tissue that is deposited early in life and continues to grow throughout ontogeny. In Urobatis, the formation of tesserae begins in the embryonic yolk sacstage of development, with agglomerations of mineralized globules coalescing in the cartilage matrix around clusters of chondrocytes [13]. The tesserae then continue to grow, increasing in both width and depth by adding new mineral at their borders throughout the life of the animal, incorporating new chondrocytes in the process $[12,13,18,51]$. The position of cell lacunae in tesserae should therefore also indicate when they were incorporated, with central cell lacunae housing the oldest tesseral cells and more recently-incorporated cells found more peripherally $[13,22]$.

When compared with morphometric data on chondrocytes in the unmineralized cartilage of Urobatis [12], our data show that the volume and density of cells do not change appreciably during mineralization (Fig. 8). This finding indicates that stingray chondrocytes neither proliferate, nor experience the drastic changes in volume (Fig. 8B) or the cell death processes that accompany cartilage mineralization in mammals [51-53]. Furthermore, the persistent chondrocyte morphology within tesserae and the halo of unmineralized cartilage matrix around chondrocytes, even once incorporated into tesserae, argues that these cells are also not transdifferentiating into bone-forming cells (i.e. those secreting Type I collagen matrix), a process which appears possible for at least some mammalian chondrocytes (reviewed in [52]).

Our results support previous suggestions that chondrocytes in elasmobranchs might participate in mineralization in a manner quite different from chondrocytes in mammals. In mammalian cartilage, hypertrophic chondrocytes have an active role during the mineralization process and bone formation, releasing enzymes to degrade the collagen matrix, producing alkaline phosphatase and Type $X$ collagen, and apoptosing or transdifferentiating at the end of the process to give way to bone and osteocytes [54,55]. In contrast, in elasmobranchs, it appears 
that chondrocytes at the mineralization front of tesserae have an active role, producing alkaline phosphatase, but never becoming hypertrophic. Also, Type $\mathrm{X}$ collagen appears to play a minor role or none at all in mineralization of tesserae [17,44,46]. Seidel et al. [13,22] noted that central cell lacunae in tesserae (i.e. likely housing the oldest tesseral cells) were in some cases completely infilled with high-mineral density tissue, suggesting that when the chondrocytes die, they release an inhibition on mineralization, similar to the process of "micropetrosis" in bone that occurs when osteocytes die [56,57]. Further research is needed to determine if tesseral chondrocytes are involved in other more active functions, for example, turnover of the mineralized matrix (i.e. a sort of 'chondrocytic chondrolysis'). Available evidence from investigations of skeletal ultrastructure, however, argues that the mineralized tissue in tesserae is not removed once deposited, even when tissue damage might demand it $[45,58,59]$.

In our data, lacunar density varied considerably among tesserae, showing a relationship to tesseral size (and therefore likely tesseral age). In particular, in wedges in contact with pores, lacunar densities could be up to 2-3x higher than non-pore wedges. Tessellated cartilage pores have been noted by several previous authors [22,60,61]; our results provide a higher-resolution perspective on these gaps in the tessellated layer, which we show are always located at the convergence point of the intertesseral joints of several tesserae. The high cellular density surrounding the pores could indicate a relation to nutritional factors, as in mammalian cartilages where chondrocyte density increases near nutrition sources (e.g. in the superficial zone of articular cartilage; [33]). The presence of possible focal nutritional sources in stingray cartilage suggests a different conception of cartilage in elasmobranchs, in contrast to other adult vertebrate cartilages, which are avascular and where cells obtain nutrients only from diffusion from cartilage surfaces [2,33]). In mammals, this mechanism of nutrient diffusion is a determinant factor for the cellular density, restricting the number of cells that can be maintained, especially in thicker cartilages [33,62]. In this way, cell density can be related to the body mass of species, being inversely related to the cartilage thickness [33]. However, the values we measured in Urobatis tesserae for lacuna densities $\left(96,788 \pm 18,083\right.$ lacunae $\left./ \mathrm{mm}^{3}\right)$, volumes $\left(649.12 \pm 382.60 \mu^{3}\right)$ and dimensions $(\bar{x}=8.27-17.33 \mu \mathrm{m})$ are consistent with chondrocytebody mass relationships observed for the articular cartilage of other vertebrate species (Fig. 8), despite the stingray having a skeleton made nearly entirely of cartilage (i.e. likely having comparatively thick cartilage regions).

Lacunae spatial organization and orientation. Although our results illustrate a great diversity of lacuna shape and size in stingray tesserae, we show that lacunae in different regions of tesserae do exhibit characteristic morphological attributes. For example, we demonstrate quantitatively the flattened morphology and 'inverted pyramid' distribution of perichondral lacunae in the 'cap zone' and the large volume of center cells, both hypothesized previously from $2 \mathrm{D}$ slice data $[13,22,63]$. Chondral lacunae were significantly rounder than other lacuna types, presenting significant differences in flatness, anisotropy and elongation relative to the lacunae of other regions. Radial lacunae were the smallest by volume, but exhibited largely intermediate flatness, anisotropy and elongation relative to other lacuna types. Radial lacunae, however, were the only lacuna type that, when several metrics of lacunar shape and size were 
considered simultaneously, could be correctly reassigned with reasonable consistency $(70.3 \%)$ to their tesseral region.

In addition to the four demonstrated tesseral regions based on cell morphology and arrangement-perichondral, central, chondral and radial zones-we illustrate that lacunae have a predominant arrangement in horizontal layers (i.e. with a dominant $Z$ axis angle of $\sim 90^{\circ}$ ) and that tesseral 'wedges' can be considered a basic subunit of tesseral structure and growth. The fact that neighboring tesserae and pores have clear influence on lacunae in wedges (Fig. 3, 6) argues they are driving factors in the growth, tissue organization and patterning of tessellated cartilage. From these observations, we hypothesize that the characteristic variation in cell shape in tesserae is linked to both structural and mechanical factors at work in the skeleton.

In mammals, cartilage and bone are typically divided into different zones according to variation in cell morphology [38,42,64-66]. The variation and three-dimensional organization in cell shape can be linked to the local architecture of the surrounding collagenous extracellular matrix and the principal directions of mechanical loading. Similar principles could be influencing cell arrangement and shape in tesserae, where the cell and lacunar morphologies apparently echo the architecture of the surrounding collagenous tissues [17]. In this way, and since tesserae are not believed to remodel, the distribution of lacunae within the mineralized matrix could be a fingerprint of the tesserae formation process and extracellular matrix organization. For example, the morphologies of central lacunae should reflect the time of formation of tesserae in the embryonic skeleton, when the unmineralized matrix is packed with large chondrocytes in high concentration [12].

As tesserae continue to grow during ontogeny, surrounding fibers and cells are incorporated into the mineralized matrix [13]. The perichondral and intertesseral matrices above and to the sides of tesserae, respectively, both comprise large, parallel bundles of Type I collagen fibers [17]; it has been observed that cells in these regions are elongated, squeezed in linear arrays between the large fiber bundles. In polarized light microscopy, these fiber bundles traverse long distances, appearing to converge on and decussate at the center of tesserae $[12,13,15,17,67-$ 69]. In contrast, the Type II collagen fibers in the unmineralized cartilage matrix abutting the 'body' zone are smaller and far less organized, perhaps reflected in the rounder and less oriented cells in the chondral portion of tesserae. These anatomical features suggest that chondrocytes in the perichondral and radial zones are constrained by the predominant fiber direction in the tissue, which in turn would argue that cell and tissue growth may use as scaffolds the fibrous architectures that are established quite early in skeletal development.

Whether cause or effect, the variation we observe in cell shape may also provide a roadmap for understanding the mechanical environment in tesserae. A cell's shape speaks to its structural interactions with its environment and the arrangement of its internal cytoskeleton, and variation in cell shape is known to affect the function of skeletal cells [19-21]. For example, in bone, asymmetric osteocyte lacunae are often aligned to the predominant loading direction, whereas more spherical osteocytes have been shown to be more mechano-sensitive and more multidirectional in their sensory capabilities than flatter, more asymmetric cells [20,21]. 
Recent models of tesserae mechanics suggest that, due to the ultrastructural anatomy of tesserae, contact stresses between adjacent tesserae will be transmitted through peripheral regions to the center [22,70]. Authors have therefore posited that central cells may have mechanical roles that differ from those of radial cells. The shape variation we show in tesserae lacunae supports these functional hypotheses: the highly-oriented peripheral cells suggest a unidirectional loading environment, in contrast with the multi-directional loads implied by the more spherical center cells. Deformations of the cytoskeleton have been shown to affect mammalian chondrocyte function and growth, playing an important role in phenotype expressions, including the chondrogenic transcription factor SOX9, production of collagen Type II (by Col2a expression) and proteoglycans (e.g. aggrecan, by ACAN expression) [20,38,71-73]. Changes in loads do not just affect the cells, but also the surrounding matrix, creating spatial variations in fluid flow, fluid pressure and electrokinetic effects such as streaming potentials [38]. In tesserae, if tissue stresses and strains are transmitted from tesseral contact (i.e. along each wedge's $X$ axis) through the mineralized tissue and/or via fluid shear in the unmineralized extracellular matrix of the LCN, the center cells may act as a switchboard to receive information from multiple directions and coordinate a growth response. Indeed, recent ultrastructural analysis suggests mineralized tissue growth is continually and locally adjusted to the changing loading environment around tesserae [22].

Summary. Our demonstration of distinct lacunar morphologies and arrangements within stingray tesserae -across different individual animals and tesserae of different shapes and sizes - and the co-alignment of lacunae between neighboring tesserae argue for guiding principles in the structuring of this skeletal system. At this stage, we can only hypothesize whether these are driven by mechanics or biology or both: John Currey mused that "[b]iologists have the double problem of determining not only how the structure of a biological material fulfils its function, but also of determining what that function is" [50]. The arrangements of lacunae and links among them offer support for the idea of a mechanosensory chondrocyte 'connectome' in tesserae (sensu [19]), but the finescale mechanics of the tissue, the physical connectivity and the sensory capability of the cells remain to be demonstrated.

\section{Acknowledgements}

The authors appreciate the chance to contribute to this special issue commemorating the life and work of John Currey. He was a friend and collaborator for several of us and will remain an inspiration, he is sorely missed. The authors would also like to thank Hubert Taieb for his help in analyzing data in AMIRA and Kady Lyons for providing samples.

\section{Funding sources}

Synchrotron beamtime allocation was provided under BESSY proposal 2012_1_111088. Development of the visual data analysis pipeline [25] and associated downstream data analyses were funded by an HFSP Young Investigator Grant (RGY0067-2013, http://www.hfsp.org/) to MND. 


\section{References}

[1] J.D. Currey, Bones: structure and mechanics, 2002.

[2] B.K. Hall, Bones and Cartilage, Academic Press, 2014.

[3] A. Teti, A. Zallone, Do osteocytes contribute to bone mineral homeostasis? Osteocytic osteolysis revisited, Bone. 44 (2009) 11-16.

[4] E.M. Aarden, E.H. Burger, P.J. Nijweide, Function of osteocytes in bone, J. Cell. Biochem. 55 (1994) 287-299.

[5] L.F. Bonewald, The amazing osteocyte, J. Bone Miner. Res. 26 (2011) 229-238.

[6] R.A. Stockwell, Chondrocytes, J. Clin. Pathol. 12 (1978) 7-13.

[7] C.W. Archer, P. Francis-West, The chondrocyte, The International Journal of Biochemistry \& Cell Biology. 35 (2003) 401-404.

[8] S. Calve, A. Ready, C. Huppenbauer, R. Main, C.P. Neu, Optical clearing in dense connective tissues to visualize cellular connectivity in situ, PLoS One. 10 (2015) e0116662.

[9] M.D. Mayan, R. Gago-Fuentes, P. Carpintero-Fernandez, P. Fernandez-Puente, P. Filgueira-Fernandez, N. Goyanes, V. Valiunas, P.R. Brink, G.S. Goldberg, F.J. Blanco, Articular chondrocyte network mediated by gap junctions: role in metabolic cartilage homeostasis, Ann. Rheum. Dis. 74 (2015) 275-284.

[10] H. Gupta, S. Schratter, W. Tesch, P. Roschger, A. Berzlanovich, T. Schoeberl, K. Klaushofer, P. Fratzl, Two different correlations between nanoindentation modulus and mineral content in the bone-cartilage interface, J. Struct. Biol. 149 (2005) 138-148.

[11] V.L. Ferguson, A.J. Bushby, A. Boyde, Nanomechanical properties and mineral concentration in articular calcified cartilage and subchondral bone, J. Anat. 203 (2003) 191-202.

[12] M.N. Dean, C.G. Mull, S.N. Gorb, A.P. Summers, Ontogeny of the tessellated skeleton: insight from the skeletal growth of the round stingray Urobatis halleri, J. Anat. 215 (2009) 227-239.

[13] R. Seidel, K. Lyons, M. Blumer, P. Zaslansky, P. Fratzl, J.C. Weaver, M.N. Dean, Ultrastructural and developmental features of the tessellated endoskeleton of elasmobranchs (sharks and rays), J. Anat. 229 (2016) 681-702.

[14] S.P. Applegate, A survey of shark hard parts, in: P.W. Gilbert, R.F. Matthewson, D.P. Rail (Eds.), Sharks, Skates and Rays, 1967: pp. 37-67.

[15] J.G. Clement, Re-examination of the fine structure of endoskeletal mineralization in chondrichthyans: implications for growth, ageing and calcium homeostasis, Aust. J. Mar. Freshw. Res. 43 (1992) 157-181.

[16] R. Seidel, A.K. Jayasankar, R. Shahar, M.N. Dean, The multiscale architectures of fish bone and tessellated cartilage and their relation to function, in: Y. Estrin, Y. Bréchet, J. Dunlop, P. Fratzl (Eds.), Architectured Materials in Nature and Engineering, 2019: pp. 329353.

[17] R. Seidel, M. Blumer, E.-J. Pechriggl, K. Lyons, B.K. Hall, P. Fratzl, J.C. Weaver, M.N. Dean, Calcified cartilage or bone? Collagens in the tessellated endoskeletons of cartilaginous fish (sharks and rays), J. Struct. Biol. 200 (2017) 54-71.

[18] M.N. Dean, J.J. Socha, B.K. Hall, A.P. Summers, Canaliculi in the tessellated skeleton of cartilaginous fishes, J. Appl. Ichthyol. 26 (2010) 263-267.

[19] R. Weinkamer, P. Kollmannsberger, P. Fratzl, Towards a connectomic description of the osteocyte lacunocanalicular network in bone, Curr. Osteoporos. Rep. 17 (2019) 186-194.

[20] R.G. Bacabac, D. Mizuno, C.F. Schmidt, F.C. MacKintosh, J.J.W.A. Van Loon, J. KleinNulend, T.H. Smit, Round versus flat: Bone cell morphology, elasticity, and mechanosensing, Journal of Biomechanics. 41 (2008) 1590-1598. 
https://doi.org/10.1016/j.jbiomech.2008.01.031.

[21] A. Vatsa, R.G. Breuls, C.M. Semeins, P.L. Salmon, T.H. Smit, J. Klein-Nulend, Osteocyte morphology in fibula and calvaria - Is there a role for mechanosensing?, Bone. 43 (2008) 452-458. https://doi.org/10.1016/j.bone.2008.01.030.

[22] R. Seidel, A. Roschger, L. Li, Q. Zhang, J. Yin, T. Yang, J.C. Weaver, P. Fratzl, P. Roschger, M.N. Dean, Mechanical properties of stingray tesserae: High-resolution correlative analysis of mineral density and indentation moduli in tessellated cartilage, Acta Biomater. 96 (2019) 421-435.

[23] K. Lyons, R. Lavado, D. Schlenk, C.G. Lowe, Bioaccumulation of organochlorine contaminants and ethoxyresorufin-O-deethylase activity in southern California round stingrays (Urobatis halleri) exposed to planar aromatic compounds, Environ. Toxicol. Chem. 33 (2014) 1380-1390.

[24] D. Stalling, M. Westerhoff, H.-C. Hege, Others, Amira: A highly interactive system for visual data analysis, The Visualization Handbook. 38 (2005) 749-767.

[25] M. Schotte, J. Chaumel, M.N. Dean, D. Baum, Image analysis pipeline for segmentation of a biological porosity network, the lacunocanalicular system in stingray tesserae, MethodsX. Submitted (2020).

[26] M.N. Dean, S. Gorb, A.P. Summers, A cryoSEM method for preservation and visualization of calcified shark cartilage (and other stubborn heterogeneous skeletal tissues), Micros. Today. 16 (2008) 48-50.

[27] T. O'Haver, Interactive peak-fitting function (peakfit.m) for Matlab or Octave, Version 9.2, June 2018. (n.d.). https://terpconnect.umd.edu/ toh/spectrum/InteractivePeakFitter.htm.

[28] B.L. Welch, On the comparison of several mean values: An alternative approach, Biometrika. 38 (1951) 330-336.

[29] M.J. Anderson, Distance-based tests for homogeneity of multivariate dispersions, Biometrics. 62 (2006) 245-253.

[30] R Core Team, R: a language and environment for statistical computing, R Foundation for Statistical Computing, Vienna, Austria, 2019.

[31] R.A. Fisher, The use of multiple measurements in taxonomic problems, Ann. Eugen. 7 (1936) 179-188.

[32] G.J. McLachlan, Discriminant Analysis and Statistical Pattern Recognition, John Wiley \& Sons, 2004.

[33] R.A. Stockwell, The interrelationship of cell density and cartilage thickness in mammalian articular cartilage, J. Anat. 109 (1971) 411.

[34] E.G.L. Bywaters, M. MacKinnon, The metabolism of joint tissues, J. Pathol. 44 (1937) 247268.

[35] E.B. Hunziker, R.K. Schenk, Physiological mechanisms adopted by chondrocytes in regulating longitudinal bone growth in rats, J. Physiol. 414 (1989) 55-71.

[36] F. Guilak, Volume and surface area measurement of viable chondrocytes in situ using geometric modelling of serial confocal sections, J. Microsc. 173 (1994) 245-256.

[37] A.M. Thompson, R.A. Stockwell, An ultrastructural study of the marginal transitional zone in the rabbit knee joint, J. Anat. 136 (1983) 701-713.

[38] F. Guilak, A. Ratcliffe, V.C. Mow, Chondrocyte deformation and local tissue strain in articular cartilage: a confocal microscopy study, J. Orthop. Res. 13 (1995) 410-421.

[39] O. Rosenthal, M.A. Bowie, G. Wagoner, Studies in the metabolism of articular cartilage. I. Respiration and glycolysis of cartilage in relation to its age, J. Cell. Comp. Physiol. 17 (1941) 221-233.

[40] G. Meachim, D.H. Collins, Cell counts of normal and osteoarthritic articular cartilage in relation to the uptake of sulphate (35SO4) in vitro, Ann. Rheum. Dis. 21 (1962) 45-50.

[41] K. Paukkonen, K. Selkainaho, J. Jurvelin, H.J. Helminen, Morphometry of articular-cartilage 
- a stereological method using light-microscopy, Anat. Rec. 210 (1984) 675-682.

[42] T.M. Quinn, E.B. Hunziker, H.-J. Hauselmann, Variation of cell and matrix morphologies in articular cartilage among locations in the adult human knee, Osteoarthritis Cartilage. 13 (2005) 672-678.

[43] K.L. Cooper, S. Oh, Y. Sung, R.R. Dasari, M.W. Kirschner, C.J. Tabin, Multiple phases of chondrocyte enlargement underlie differences in skeletal proportions, Nature. 495 (2013) 375-378.

[44] S. Omelon, J. Georgiou, F. Variola, M.N. Dean, Colocation and role of polyphosphates and alkaline phosphatase in apatite biomineralization of elasmobranch tesserae, Acta Biomater. 10 (2014) 3899-3910.

[45] M.N. Dean, L. Ekstrom, E. Monsonego-Ornan, J. Ballantyne, P.E. Witten, C. Riley, W. Habraken, S. Omelon, Mineral homeostasis and regulation of mineralization processes in the skeletons of sharks, rays and relatives (Elasmobranchii), Semin. Cell Dev. Biol. 46 (2015) 51-67.

[46] M. Debiais-Thibaud, P. Simion, S. Ventéo, D. Muñoz, S. Marcellini, S. Mazan, T. Haitina, Skeletal mineralisation in association with type $X$ collagen expression is an ancestral feature for jawed vertebrates, Mol. Biol. Evol. (2019). https://doi.org/10.1093/molbev/msz145.

[47] B.F. Eames, N. Allen, J. Young, A. Kaplan, J.A. Helms, R.A. Schneider, Skeletogenesis in the swell shark Cephaloscyllium ventriosum, J. Anat. 210 (2007) 542-554.

[48] S. Enault, D.N. Muñoz, W.T.A.F. Silva, V. Borday-Birraux, M. Bonade, S. Oulion, S. Marcellini, S. Ventéo, M. Debiais-Thibaud, Molecular footprinting of skeletal tissues in the catshark Scyliorhinus canicula and the clawed frog Xenopus tropicalis identifies conserved and derived features of vertebrate calcification, Front. Genet. 6 (2015) 1-14.

[49] M.J. Duer, T. Friscić, R.C. Murray, D.G. Reid, E.R. Wise, The mineral phase of calcified cartilage: its molecular structure and interface with the organic matrix, Biophys. J. 96 (2009) 3372-3378.

[50] J.D. Currey, The design of mineralised hard tissues for their mechanical functions, J. Exp. Biol. 202 (1999) 3285-3294.

[51] M. Egerbacher, M. Helmreich, E. Mayrhofer, P. Böck, Mineralisation of the hyaline cartilage in the small-spotted dogfish Scyliorhinus canicula L, Scr. Med. 79 (2006) 199-212.

[52] R.J. Hinton, Y. Jing, J. Jing, J.Q. Feng, Roles of chondrocytes in endochondral bone formation and fracture repair, J. Dent. Res. 96 (2017) 23-30.

[53] E.J. Mackie, L. Tatarczuch, M. Mirams, The skeleton: a multi-functional complex organ. The growth plate chondrocyte and endochondral ossification, Journal of Endocrinology. 211 (2011) 109-121. https://doi.org/10.1530/joe-11-0048.

[54] T.E. Cawston, A.J. Wilson, Understanding the role of tissue degrading enzymes and their inhibitors in development and disease, Best Pract. Res. Clin. Rheumatol. 20 (2006) 9831002.

[55] E.J. Mackie, Y.A. Ahmed, L. Tatarczuch, K.S. Chen, M. Mirams, Endochondral ossification: How cartilage is converted into bone in the developing skeleton, Int. J. Biochem. Cell Biol. 40 (2008) 46-62.

[56] H.M. Frost, Micropetrosis, J. Bone Joint Surg. Am. 42 (1960) 144-150.

[57] V.T. Carpentier, J. Wong, Y. Yeap, C. Gan, P. Sutton-Smith, A. Badiei, N.L. Fazzalari, J.S. Kuliwaba, Increased proportion of hypermineralized osteocyte lacunae in osteoporotic and osteoarthritic human trabecular bone: Implications for bone remodeling, Bone. 50 (2012) 688-694.

[58] M.N. Dean, J.J. Bizzarro, B. Clark, C.J. Underwood, Z. Johanson, Large batoid fishes frequently consume stingrays despite skeletal damage, Royal Society Open Science. 4 (2017) 170674-170611. 
[59] D. Ashhurst, The cartilaginous skeleton of an elasmobranch fish does not heal, Matrix Biol. 23 (2004) 15-22.

[60] J.G. Maisey, The diversity of tessellated calcification in modern and extinct chondrichthyans, Revue de Paléobiologie, Genève. 32 (2013) 355-371.

[61] D. Knötel, R. Seidel, S. Prohaska, M.N. Dean, D. Baum, Automated segmentation of complex patterns in biological tissues: Lessons from stingray tessellated cartilage, PLoS One. 12 (2017) e0188018-24.

[62] J. Malda, J.C. de Grauw, K.E.M. Benders, M.J.L. Kik, C.H.A. van de Lest, L.B. Creemers, W.J.A. Dhert, P.R. van Weeren, Of mice, men and elephants: The relation between articular cartilage thickness and body mass, PLoS One. 8 (2013) e57683.

[63] N. Kemp, S.K. Westrin, Ultrastructure of calcified cartilage in the endoskeletal tesserae of sharks, J. Morphol. 160 (1979) 75-101.

[64] E. Hunziker, Quantitative structural organization of normal adult human articular cartilage, Osteoarthritis Cartilage. 10 (2002) 564-572.

[65] M. Kerschnitzki, W. Wagermaier, P. Roschger, J. Seto, R. Shahar, G.N. Duda, S. Mundlos, P. Fratzl, The organization of the osteocyte network mirrors the extracellular matrix orientation in bone, Journal of Structural Biology. 173 (2010) 303-311.

[66] M. Kerschnitzki, P. Kollmannsberger, M. Burghammer, G.N. Duda, R. Weinkamer, W. Wagermaier, P. Fratzl, Architecture of the osteocyte network correlates with bone material quality, J. Bone Miner. Res. 28 (2013) 1837-1845.

[67] W. Bargmann, Zur Kenntnis der Knorpelarchitekturen, Z. Zellforch. Microsk. Anat. Histochem. 29 (1939) 405-424.

[68] W. Roth, Beiträge zur Kenntnis der Strukturverhältnisse des Selachier-Knorpels, Morphologisches Jahrbuch. (1911) 485-555.

[69] W.J. Schmidt, Über die Verkalkung des Knorpelgewebes der Haie, Z. Zellforsch. Mikrosk. Anat. 37 (1952) 377-388.

[70] A.K. Jayasankar, R. Seidel, A. Hosny, J.C. Weaver, P. Fratzl, J. Chen, M.N. Dean, Multiscale modeling and mechanical performance characterization of stingray skeleton-inspired tessellations, J. Mech. Phys. Solids. In review (2019).

[71] A. Woods, G. Wang, F. Beier, Regulation of chondrocyte differentiation by the actin cytoskeleton and adhesive interactions, J. Cell. Physiol. 213 (2007) 1-8.

[72] N. Wang, J.P. Butler, D.E. Ingber, Mechanotransduction across the cell surface and through the cytoskeleton, Science. 260 (1993) 1124-1127.

[73] K. von der Mark, V. Gauss, H. von der Mark, P. Müller, Relationship between cell shape and type of collagen synthesised as chondrocytes lose their cartilage phenotype in culture, Nature. 267 (1977) 531-532. 